\title{
Evaluating the Effects of Façade Greening on Human Bioclimate in a Complex Urban Environment
}

\author{
Britta Jänicke, ${ }^{1}$ Fred Meier, ${ }^{1}$ Marie-Therese Hoelscher, ${ }^{2}$ and Dieter Scherer ${ }^{1}$ \\ ${ }^{1}$ Chair of Climatology, Department of Ecology, Berlin Institute of Technology, Rothenburgstraße 12, 12165 Berlin, Germany \\ ${ }^{2}$ Chair of Soil Conservation, Department of Ecology, Berlin Institute of Technology, Ernst-Reuter-Platz 1, 10587 Berlin, Germany
}

Correspondence should be addressed to Britta Jänicke; britta.jaenicke@tu-berlin.de

Received 26 September 2014; Revised 19 December 2014; Accepted 19 December 2014

Academic Editor: Tzu-Ping Lin

Copyright (C) 2015 Britta Jänicke et al. This is an open access article distributed under the Creative Commons Attribution License, which permits unrestricted use, distribution, and reproduction in any medium, provided the original work is properly cited.

\begin{abstract}
The evaluation of the effectiveness of countermeasures for a reduction of urban heat stress, such as façade greening, is challenging due to lacking transferability of results from one location to another. Furthermore, complex variables such as the mean radiant temperature $\left(T_{\mathrm{mrt}}\right)$ are necessary to assess outdoor human bioclimate. We observed $T_{\mathrm{mrt}}$ in front of a building façade in Berlin, Germany, which is half-greened while the other part is bare. $T_{\text {mrt }}$ was reduced (mean $2 \mathrm{~K}$ ) in front of the greened compared to the bare façade. To overcome observational shortcomings, we applied the microscale models ENVI-met, RayMan, and SOLWEIG. We evaluated these models based on observations. Our results show that $T_{\mathrm{mrt}}(\mathrm{MD}=-1.93 \mathrm{~K})$ and downward short-wave radiation $\left(\mathrm{MD}=14.39 \mathrm{~W} / \mathrm{m}^{2}\right)$ were sufficiently simulated in contrast to upward short-wave and long-wave radiation. Finally, we compare the simulated reduction of $T_{\text {mrt }}$ with the observed one in front of the façade greening, showing that the models were not able to simulate the effects of façade greening with the applied settings. Our results reveal that façade greening contributes only slightly to a reduction of heat stress in front of building façades.
\end{abstract}

\section{Introduction}

Heat stress risk in cities threatens human health [1] and effective countermeasures are not clearly identified. Even though many measures to reduce outdoor urban heat stress are proposed from various disciplines and at different spatial scales [2], their effectiveness is still disputed. Assessing the effectiveness of countermeasures is challenging for many reasons. For example, the transferability of results from one location to another is limited due to the complexity of the urban system and various climates [3]. Moreover, the impact of a countermeasure on outdoor human bioclimate cannot be described sufficiently by simple climate elements, such as surface or air temperature. The mean radiant temperature $\left(T_{\mathrm{mrt}}\right)$ is an important variable for the assessment of human bioclimate in urban environments because it includes long-wave and short-wave radiation that reaches the human body $[4,5]$.

Façade greening is a promising countermeasure to reduce urban heat. It can be attached to a large area in cities [6] and features several cobenefits, such as insulating buildings [7-9] or serving as habitat for wildlife [6]. The knowledge about the effectiveness of façade greening to reduce outdoor heat stress risks, however, is still incomplete due to limits in transferring of results to other sites [10]. The cooling effects of façade greening regarding surface and air temperature depend on solar irradiance, vegetation properties, and the particular greening system [11-13]. Also, the mechanisms of cooling (e.g., through shadowing or transpiration) vary between different plant species [13]. The effects of façade greening on air temperature were found to be small to negligible $[7,11,14]$. Wall temperatures decreased more strongly $[14,15]$ as well as the emitted long-wave radiation [16]. $T_{\mathrm{mrt}}$ was reduced by $2 \mathrm{~K}$ to $13 \mathrm{~K}$ in the tropics [15], but the effects for other locations are unknown. Studies that quantify the influence of façade greening on $T_{\text {mrt }}$ are rare [15] because so far architecture and engineering disciplines are dominant with a focus on air and surface temperature and its influence on the building [10].

Microclimate models can be applied to expand the knowledge of the effects of façade greening on human bioclimate. Microclimate models, such as ENVI-met, RayMan, or 
SOLWEIG, are often used in different disciplines. Particularly over the last few years, the number of studies applying ENVImet and RayMan has grown rapidly. This is an encouraging trend as it may present an increasing awareness of the topic of human bioclimate in cities and may accelerate the implementation of countermeasures. Nevertheless, the reliability and the uncertainty of the results from studies solely based on simulations may vary appreciably. The deviations between observations and simulations have sparsely been evaluated in a comprehensive way. Thus, the inaccuracies in simulating countermeasures or real case situations are insufficiently known even apart from the special case of façade greening. A comparison of $T_{\text {mrt }}$ simulated by ENVI-met, RayMan, and SOLWEIG under the same conditions was so far performed by Chen et al. [17]. Other variables, such as short-wave and long-wave radiation, did not undergo an intercomparison [36].

So far the models have not been applied to simulate façade greening and we are not aware of other models that are able to simulate façade greening with regard to outdoor human bioclimate. ENVI-met, RayMan, and SOLWEIG include plants, but specific vegetation types, such as façade greening, are not explicitly declared to be supported. Nevertheless, all of the models should be able to consider some aspects of façade greening. RayMan supports different trees with a specific emissivity and albedo as well as changes due to vegetation in the sky view factor (SVF). Thus, albedo and emissivity are modified due to façade greening. SOLWEIG considers vegetation in SVF and reduction of short-wave radiation through transmissivity and sets sunlit leaf temperatures to air temperature. Hence, especially long-wave radiation is expected to alternate in front of a building with façade greening. ENVI-met moreover simulates evapotranspiration. Thus, several effects of façade greening are expected to be reproduced, such as changes in SVF, increased water-vapor fluxes, decreased long-wave radiation, or modified shortwave radiation.

In order to study the effects of façade greening on outdoor human bioclimate, we will firstly use observational data to answer the following question: (1) How large is the reduction of $T_{\text {mrt }}$ in front of a greened façade compared to a bare one at a study site? Afterwards, we will apply the models ENVImet, RayMan, and SOLWEIG to the same site in order to (2) evaluate the general performance of the models in simulating $T_{\mathrm{mrt}}$ and other variables relevant to assess human bioclimate. Thereby, we will contribute to the intercomparison and evaluation of these models in a complex urban environment. Finally, we investigate (3) if the models are able to simulate the observed alteration of $T_{\mathrm{mrt}}$ in front of the façade greening. In a wider sense the last question addresses if microclimate models are able to represent specific types of urban vegetation such as façade greening.

\section{Material and Methods}

2.1. Study Site. In order to observe and simulate the effects of façade greening on $T_{\mathrm{mrt}}$, we chose a south-southwest oriented building facade, which is half-covered with Parthenocissus tricuspidata while the other part is bare. The façade is located at the campus of the Berlin Institute of Technology, Germany, Hardenbergstaße 38 (52.5112N, 13.3241E, 31-35 m above sea level), in a compact midrise zone (Local Climate Zone 2) [37]. Parthenocissus tricuspidata covers the building wall from the bottom to the top ( $9 \mathrm{~m}$ ) and nearly half of the building width $(11 \mathrm{~m})$. The plants are attaching themselves to the façade without technical climbing support. They rooted in a raised bed on the west oriented side of the building (unsealed area about $6 \mathrm{~m}^{2}$ ). The substrate consists of loamy sand. The plants are irrigated in irregular intervals, but we irrigated the cavity before the measurement campaign to guarantee sufficient water supply. The albedo (calculated from observations on 7, 23, 2013, 1000-1600 Central European Time, CET) is 0.36 in front of the bare building wall, 0.28 in front of the façade greening, and 0.18 for the ground surface. The mean depth of the vegetation layer is $0.27 \pm 0.08 \mathrm{~m}$ (Table 1 ). The average leaf area density (LAD) of the façade greening is $1.85 \mathrm{~m}^{2} / \mathrm{m}^{3}$ according to our measurements at one vertical transect of $1 \mathrm{~m} \times 9 \mathrm{~m}$. On $8,19,2013$, we harvested all leaves at this vertical transect and measured the depth of the vegetation layer and the size of all leaves with an area meter (Model 3100, LI-COR, Inc.).

2.2. Observation. We measured on 7, 23, 2013 (00-23 CET), in front of the building façade. This day was characterized by clear sky conditions and high air temperatures (Figure 1). The measurements comprised mobile integral radiation measurements as well as wind speed, relative humidity, air temperature, and several other variables to initialize ENVImet, such as soil and indoor temperature (Figure 2).

The mobile measurements quantified $T_{\text {mrt }}$ using integral radiation measurements based on three ventilated net radiometers (CNR4, Kipp \& Zonen Corp., accuracy $\pm 10 \%$ for daily totals) and the calculation of angular factors with the formula by Thorsson et al. [4] ((1) and (2)). Equation (1) summarizes the long- and short-wave radiations from the bottom, the top, and the four cardinal points. The variables were weighted according to the angular factors in order to estimate the shape of a standing person. Afterward $T_{\text {mrt }}$ was calculated from mean radiant flux density $\left(S_{\text {str }}\right)$ with the Stefan-Boltzmann law (2). The net radiometers were oriented along the façade, which means towards north-northeast (NNE) and not towards the main cardinal points:

$$
\begin{aligned}
S_{\mathrm{str}} & =\alpha_{k} \int_{i=1}^{6} K_{i} F_{i}+\varepsilon_{p} \int_{i=1}^{6} L_{i} F_{i}, \\
T_{\mathrm{mrt}} & =\sqrt[4]{\frac{S_{\mathrm{str}}}{\left(\varepsilon_{p} \sigma\right)}}-273.15,
\end{aligned}
$$

where $F_{i}=$ angular factors for weighting the radiation fluxes ( 0.06 for up- and downward and 0.22 for the cardinal points), $K_{i}=$ short-wave radiation $\left(\mathrm{W} / \mathrm{m}^{2}\right), L_{i}=$ long-wave radiation $\left(\mathrm{W} / \mathrm{m}^{2}\right), \alpha_{k}=$ absorption coefficient of short-wave radiation (0.07), $\varepsilon_{p}=$ the emissivity of the human body (0.97), and $\sigma=$ the Stefan-Boltzmann constant $\left(5.67 \cdot 10^{-8} \mathrm{~W} / \mathrm{m}^{2} \mathrm{~K}^{-4}\right)$. 
TABLE 1: Leaf area density (LAD) and depth of the façade greening based on a vertical transect of $(1 \mathrm{~m} \times 9 \mathrm{~m})$.

\begin{tabular}{lcccccccccc}
\hline Height $(\mathrm{m})$ & $0-1$ & $1-2$ & $2-3$ & $3-4$ & $4-5$ & $5-6$ & $6-7$ & $7-8$ & $8-9$ & Mean \\
\hline LAD $\left(\mathrm{m}^{2} / \mathrm{m}^{3}\right)$ & 1.91 & 2.52 & 2.02 & 1.90 & 1.88 & 1.81 & 1.77 & 1.51 & 1.32 & $\mathbf{1 . 8 5}$ \\
Depth $(\mathrm{m})$ & 0.34 & 0.36 & 0.30 & 0.26 & 0.30 & 0.34 & 0.22 & 0.18 & 0.13 & $\mathbf{0 . 2 7}$ \\
\hline
\end{tabular}

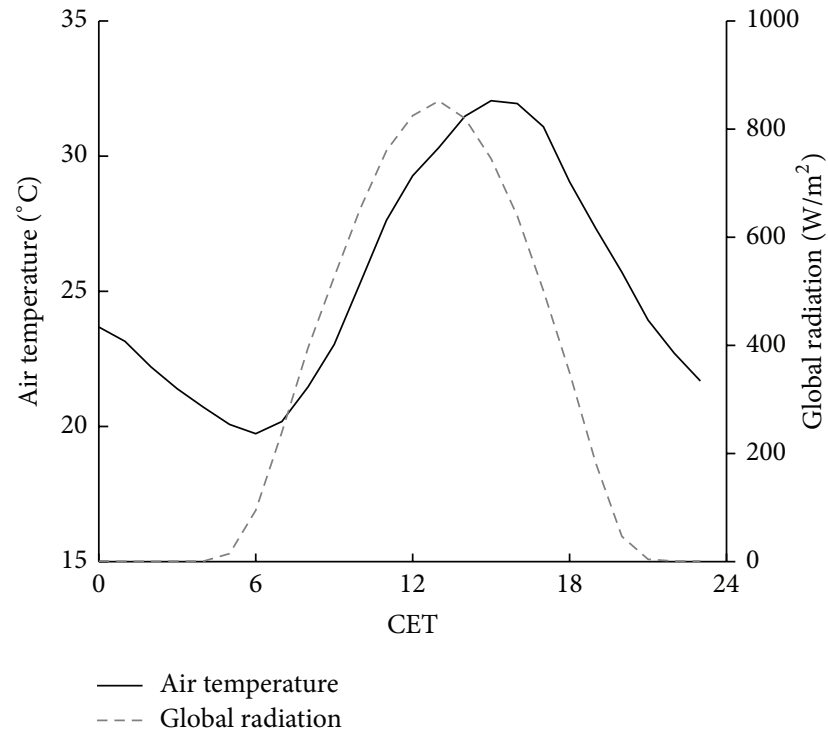

FIGURE 1: Air temperature in front of the façade and global radiation during the measurement campaign $(7,23,2013)$.

The mobile station also included a ventilated temperature and relative humidity sensor (CS215, Campbell Scientific Inc., accuracy $\pm 0.4^{\circ} \mathrm{C}$ for +5 to $+40^{\circ} \mathrm{C}$ and $\pm 4 \%$ for 0 to $\left.100 \%\right)$. The station was set up at a distance of $1.2 \mathrm{~m}$ to the building. The measurement height was $1.1 \mathrm{~m}$. We moved the station every $15 \mathrm{~min}$ between the greened and the bare site and aggregated the observed data afterwards from a minutely to an hourly resolution for each site (Figure 2).

Additional measurements especially for initializing ENVI-met comprised soil temperatures at a depth of $0.3 \mathrm{~m}$, $0.2 \mathrm{~m}$, and $0.1 \mathrm{~m}$ (analog mercury-thermometers), soil humidity (TDR probes) with a resolution of $10 \mathrm{~min}$, and indoor air temperatures averaged over four rooms (Testo $174 \mathrm{H}$, Testo $\mathrm{AG}$, accuracy $\pm 0.5^{\circ} \mathrm{C}$ for -20 to $+70^{\circ} \mathrm{C}$ ) with a 5 min resolution. Furthermore, short-wave transmissivity through the leaves was measured at two heights, each with two pyranometers, one behind and the other one in front of the greening (SP 110, Apogee). Mean transmissivity was 0.28 . Off-site observations of global radiation and wind speed were carried out above roof level at the department of ecology $(52.4572 \mathrm{~N}, 13.3158 \mathrm{E})$ with a distance of about $6 \mathrm{~km}$ to the study site.

2.3. Models and Simulation. For the same day (7, 23, 2013, 00-23 CET), we applied the microclimate models: ENVImet Version 3.1 Beta 5, ENVI-met Version 4.0 Preview [18, 38], SOLWEIG 2013a [24, 25], and RayManPro [22, 23].
The façade greening was introduced into the models as a flat plant in front of the building with leaves from ground to top. Furthermore, we specified plant parameters (albedo, transmissivity, LAD, etc.) to represent the façade greening as later described for the different models.

In order to analyze the influence of predefined meteorological data from observations and to compare it to the calculations by the models, we performed seven experiments (Table 2). The current version of ENVI-met 3 (E0a) does not support forcing of air temperature and relative humidity and thus additionally the unreleased version 4.0 Preview was applied (E0 unforced and E1 forced). The new version has already been used in other publications [33, 34, 39]. SOLWEIG and RayMan require predefined values of air temperature and relative humidity. Both models can calculate short-wave downward radiation internally, which is the maximum short-wave downward radiation that can be derived at the specific date and location without clouds. These estimated values are used as global radiation to create experiments (R0 and S0) without measurement data of global radiation.

Building data for the input files was generated from the $3 \mathrm{D}$ city model of Berlin, which is available in the CityGML data format (http://www.citygml.org). We derived the spatial distribution and the height of vegetation from the Urban and Environmental Information System by the Senate Department for Urban Development and the Environment, Berlin. Terrain is neglected in all simulations because ENVImet 3 does not support it. Furthermore, we assume its effects to be negligible due to the flat terrain at the study site. Meteorological data for the simulation were derived from onsite observations averaged between the greened and the bare sites in front of the façade for all variables with the exceptions of wind speed, wind direction, and global radiation. To initialize ENVI-met, daily mean values were applied.

2.3.1. ENVI-met. ENVI-met is a CFD model for simulating surface-plant-air interactions from micro- to local scale with a focus on urban environments [18, 38, 40]. It requires intensive computational resources of a personal computer as each of the experiments lasted over 10 days. ENVI-met is, in contrast to RayMan and SOLWEIG, able to simulate the physiological processes of vegetation and to describe vegetation not only as a porous obstacle.

The domain in ENVI-met had a spatial resolution of $1 \mathrm{~m} \times 1 \mathrm{~m}$ and consisted of $110 \times 80$ grid points after removing 30 nesting grid points at each border. The domain size in ENVI-met was limited. Thus, the model domain is smaller than in SOLWEIG and RayMan. We used telescoping grids (factor 15\%) starting at $2 \mathrm{~m}$ to include the highest building $(43 \mathrm{~m})$ because vertical grids were limited to 30 layers. In ENVI-met the wind field and turbulent heat flux were simulated as well. Therefore, the model domain needed to be 
TABLE 2: Overview of the input parameters and model settings in the seven experiments. " $\mathrm{X}$ " represents input of times series of meteorological data.

\begin{tabular}{|c|c|c|c|c|c|c|c|c|}
\hline \multirow{2}{*}{ Input parameter } & Name & E0a & E0 & E1 & R0 & $\mathrm{R} 1$ & S0 & S1 \\
\hline & Model & ENVI-met 3 & \multicolumn{2}{|c|}{ ENVI-met 4} & \multicolumn{2}{|c|}{ RayMan } & \multicolumn{2}{|c|}{ SOLWEIG } \\
\hline Meteorological data: initial & Unit & & & & & & & \\
\hline Wind speed $(10 \mathrm{~m})$ & $\mathrm{m} / \mathrm{s}$ & 2.3 & 2.3 & 2.3 & - & - & - & - \\
\hline Wind direction $(10 \mathrm{~m})$ & $\operatorname{deg}$ & 57.0 & 57.0 & 57.0 & - & - & - & - \\
\hline Potential air temperature $(2500 \mathrm{~m})$ & ${ }^{\circ} \mathrm{C}$ & 24.85 & 24.85 & 24.85 & - & - & - & - \\
\hline Specific humidity (2500 m) & $\mathrm{g} / \mathrm{kg}$ & 8.56 & 8.56 & 8.56 & - & - & - & - \\
\hline Relative humidity (2 m) & $\%$ & 45.8 & 45.8 & - & - & - & - & - \\
\hline \multicolumn{9}{|l|}{ Meteorological data } \\
\hline Air temperature $(1.1 \mathrm{~m})$ & ${ }^{\circ} \mathrm{C}$ & - & - & $\mathrm{X}$ & $\mathrm{X}$ & $\mathrm{X}$ & $\mathrm{X}$ & $\mathrm{X}$ \\
\hline Relative humidity $(1.1 \mathrm{~m})$ & $\%$ & - & - & $\mathrm{X}$ & $\mathrm{X}$ & $\mathrm{X}$ & $\mathrm{X}$ & $\mathrm{X}$ \\
\hline Global radiation & $\mathrm{W} / \mathrm{m}^{2}$ & - & - & - & - & $\mathrm{X}$ & - & $\mathrm{X}$ \\
\hline \multicolumn{9}{|l|}{ Soil data } \\
\hline Initial soil temperature $(0-50 \mathrm{~cm})$ & ${ }^{\circ} \mathrm{C}$ & $23.10-25.71$ & $23.10-25.71$ & $23.10-25.71$ & - & - & - & - \\
\hline Relative soil humidity $(0-50 \mathrm{~cm})$ & $\%$ & 25.00 & 25.00 & 25.00 & - & - & - & - \\
\hline \multicolumn{9}{|l|}{ Environmental parameter } \\
\hline Albedo surroundings & - & - & - & - & 0.30 & 0.30 & 0.36 & 0.36 \\
\hline Albedo (wall) & - & 0.36 & 0.36 & 0.36 & - & - & - & - \\
\hline Albedo (roof) & - & 0.20 & 0.20 & 0.20 & - & - & - & - \\
\hline Albedo (plant) & - & 0.28 & 0.28 & 0.28 & 0.28 & 0.28 & - & - \\
\hline Transmissivity of vegetation & - & - & - & - & - & - & 0.28 & 0.28 \\
\hline Emissivity (ground) & - & - & - & - & - & - & 0.95 & 0.95 \\
\hline Emissivity (walls) & - & - & - & - & - & - & 0.90 & 0.90 \\
\hline Bowen ratio & - & - & - & - & 1.00 & 1.00 & - & - \\
\hline Solar adjustment factor & - & 0.85 & 0.85 & 0.85 & - & - & - & - \\
\hline
\end{tabular}
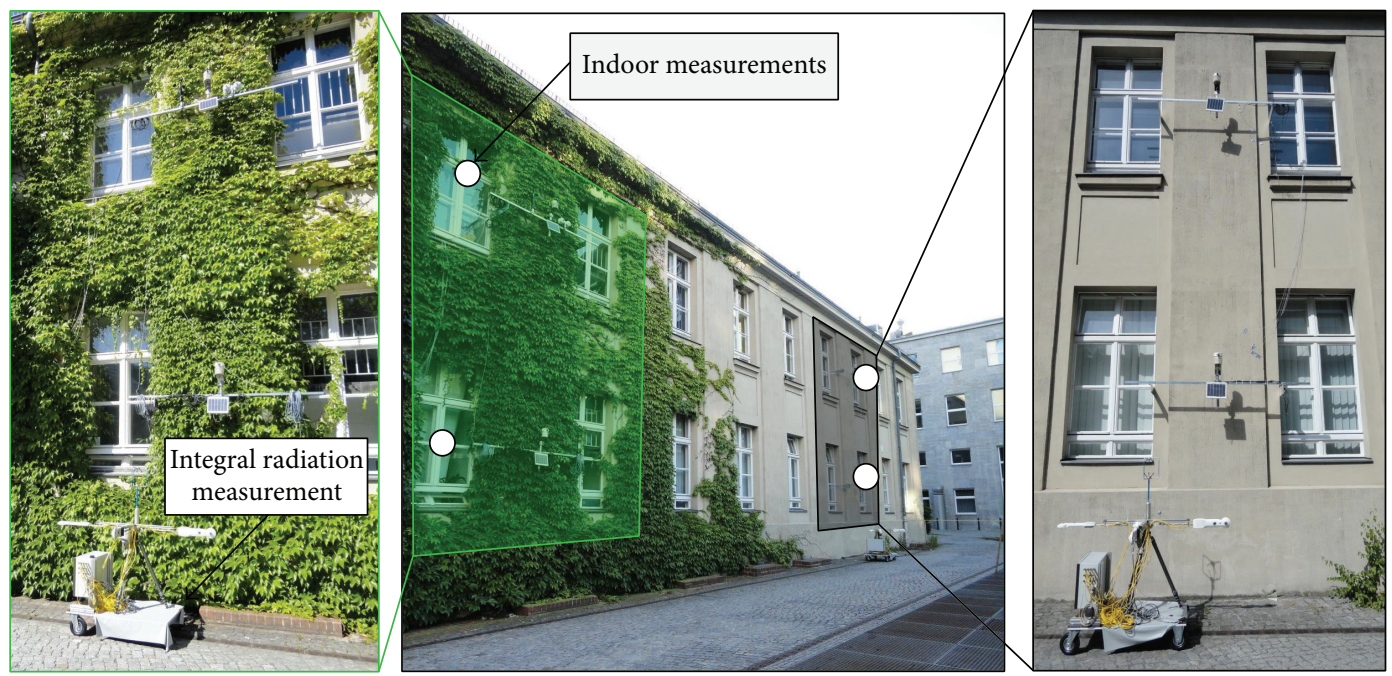

FIGURE 2: Measurement arrangement and study site in Berlin, Germany.

rotated by $30^{\circ}$ to avoid unrealistic roughness at the edges of the building walls (Figure 3 ). With the high resolution vegetation data, we introduced new vegetation classes based on the default plant database of ENVI-met to account for vegetation heights with a resolution of $1 \mathrm{~m}$. The façade greening was also introduced as a new class with the measured LAD values
(Table 1). We interpolated the 9 measured levels to 10 relative height levels to adapt to the structure of ENVI-met's plant database (see Table 3). According to on-site experiences, soils beneath vegetation were classified as loamy sand, streets as asphalt, areas beneath buildings as pavement, and nonstreet areas as light brick roads. 
TABLE 3: Measured leaf area density (LAD) profile of façade greening (bold) and assumed parameter for the plant database in ENVI-met.

\begin{tabular}{|c|c|c|c|c|c|c|c|c|c|c|c|c|c|c|c|}
\hline \multirow{2}{*}{ Plant } & \multirow{2}{*}{ Type } & \multirow{2}{*}{ Albedo } & \multirow{2}{*}{ Height (m) } & \multirow{2}{*}{ Root zone $(\mathrm{m})$} & \multicolumn{10}{|c|}{ Leaf area density (LAD) at level } & \multirow{2}{*}{$\begin{array}{l}\text { Root area density, all } \\
\text { levels }\end{array}$} \\
\hline & & & & & 1 & 2 & 3 & 4 & 5 & 6 & 7 & 8 & 9 & 10 & \\
\hline Trees & $\begin{array}{l}\text { Deciduous } \\
\text { trees }\end{array}$ & 0.28 & $6-31$ & 2 & 0 & 0 & 0 & 0.2 & 0.7 & 2.2 & 2.2 & 2.0 & 1.7 & 0.4 & 0.1 \\
\hline $\begin{array}{l}\text { Façade } \\
\text { greening }\end{array}$ & $\begin{array}{l}\text { Deciduous } \\
\text { trees }\end{array}$ & 0.28 & 9 & 1 & 1.9 & 2.5 & 2.1 & 1.9 & 1.9 & 1.9 & 1.8 & 1.7 & 1.5 & 1.3 & 0.1 \\
\hline
\end{tabular}

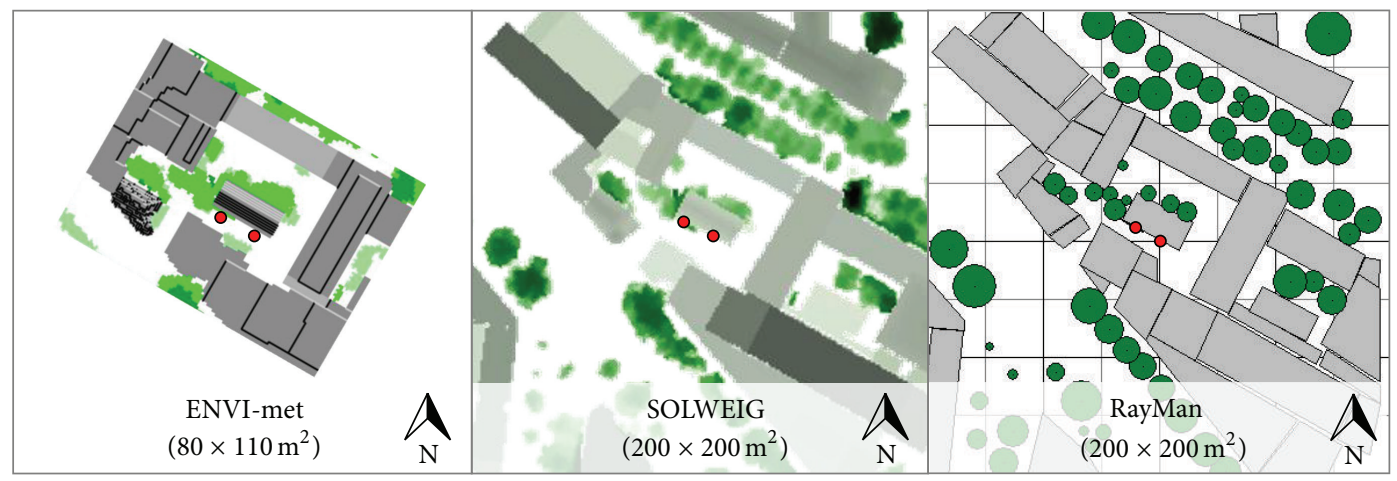

FIGURE 3: Model domains of the different models. In the domain of SOLWEIG, dark colors represent taller buildings and vegetation compared to pale colors. Red circles indicate the greened and the bare site of observation and analyses.

2.3.2. SOLWEIG. SOLWEIG simulates radiation fluxes and $T_{\mathrm{mrt}}$ based on digital surface models $[24,25]$. In contrast to ENVI-met and RayMan, SOLWEIG calculates shadow patterns and consequently $T_{\mathrm{mrt}}$ for the middle of an hour; thus meteorological input was averaged accordingly. Vegetation and building data were also compiled with a resolution of $1 \mathrm{~m}$. SOLWEIG uses trunk zones to calculate shadow patterns of vegetation, which were about $30 \%$ of the vegetation height at the study site. The façade greening was represented as a flat plant without a trunk characterized by the observed values of albedo and transmissivity. In order to generate a SOLWEIG run (S0) without measurement data of global radiation, SOLWEIG1D was used. SOLWEIG1D calculates the maximum global radiation for the geographical location, which SOLWEIG2013a is not able to do.

2.3.3. RayMan. Matzarakis et al. [22] developed the model RayMan (RayMan Pro 2.2) to calculate $T_{\text {mrt }}$ and biometeorological indices in complex environments. The building and vegetation data were created manually with the supplied editor on the basis of the digital surface models. Due to this approach, buildings had a flat roof in RayMan. In contrast to SOLWEIG and ENVI-met, RayMan calculates fluxes only for one point of interest. Thus, two obstacle files were used with different center points. Similar to SOLWEIG, RayMan can calculate global radiation itself. Consequently, we did experiments with calculated (R0) and measured global radiation ( $\mathrm{R} 1)$. The façade greening was represented as series of plants in front of the building with a diameter of $1 \mathrm{~m}$, a trunk length of $0 \mathrm{~m}$, and an albedo of 0.28 .

2.4. Analyses. The analyses of the simulation results refer to two points in front of the façade in each model domain, the greened site and the bare site (Figure 3). For the model evaluation (Section 3.2), time series plots are only presented for the greened site, but the statistical analysis includes both sites.

The models that did not calculate a specific climate element (e.g., air temperature) were excluded for the section. Long-wave radiation from RayMan and ENVI-met was calculated from surface temperatures using the Stefan-Boltzmann law (with an emissivity of 0.95 ).

The selected statistical measures for the model evaluation are a combination of generally recommended ones [41, 42] and the ones mostly found in former studies (e.g., coefficient of determination $\left(r^{2}\right)$ ). Root-mean-square deviation (RMSD), mean deviation (MD), and mean absolute deviation (MAD) were calculated as described by Schlünzen and Sokhi [42]. For all statistical analyses we used IDL 8.2.2 (20072012 Exelis Visual Information Solutions, Inc.) and the library “Coyote" (1996-2014 Fanning Software Consulting, Inc.).

\section{Results}

3.1. Measuring the Effects of Façade Greening on $T_{m r t} . T_{\mathrm{mrt}}$ decreased by $2.13 \mathrm{~K}(1000-1600 \mathrm{CET}, 7,23,2014)$ in front of the greened façade compared to the bare one (Figure 4). The components for calculating $T_{\text {mrt }}$ varied slightly between both sites and not only the short-wave radiation reflected and the long-wave radiation emitted from the façade from NNE (Figure 5). Thus, the sums of short-wave and long-wave radiation downward, upward, and from the cardinal points differed between the bare and the greened site (Table 4). Nevertheless, long-wave radiation emitted from the greened site is clearly lower compared to the bare one. 
TABLE 4: Sum (00-23 CET) of long- and short-wave radiation at the greened and the bare site up- and downward (up, down) and from the cardinal points (west-northwest (WNW), east-southeast (ESE), south-southwest (SSW), and north-northwest (NNE) (direction from the façades)) on 7, 23, 2013. $F_{i}$ is the angular factor used in calculation of mean radiant temperature (0.06 for up- and downward radiation and 0.22 for radiation from the cardinal points).

\begin{tabular}{lcccccccc}
\hline \multirow{2}{*}{ Direction } & \multicolumn{4}{c}{ Sum of short-wave radiations $\left(\mathrm{MJ} \mathrm{d}^{-1}\right)$} & \multicolumn{3}{c}{ Sum of long-wave radiations $\left(\mathrm{MJ} \mathrm{d}^{-1}\right)$} \\
& Bare & Greened & ${ }^{\Delta}$ Bare-greened & ${ }^{\Delta}$ Bare-greened $\times F_{i}$ & Bare & Greened & ${ }^{\Delta}$ Bare-greened & ${ }^{\Delta}$ Bare-greened $\times F_{i}$ \\
\hline Down & 22.36 & 20.12 & 2.24 & 0.13 & 36.20 & 35.88 & 0.31 & 0.02 \\
Up & 4.35 & 3.57 & 0.78 & 0.05 & 43.02 & 42.04 & 0.99 & 0.06 \\
WNW & 8.67 & 6.11 & 2.56 & 0.56 & 39.92 & 39.60 & 0.33 & 0.07 \\
ESE & 10.93 & 10.39 & 0.54 & 0.12 & 40.49 & 39.62 & 0.87 & 0.19 \\
SSW & 14.27 & 13.44 & 0.83 & 0.18 & 39.36 & 38.81 & 0.55 & 0.12 \\
NNE & 5.03 & 3.54 & 1.49 & 0.33 & 42.29 & 39.92 & 2.37 & 0.52 \\
\hline
\end{tabular}

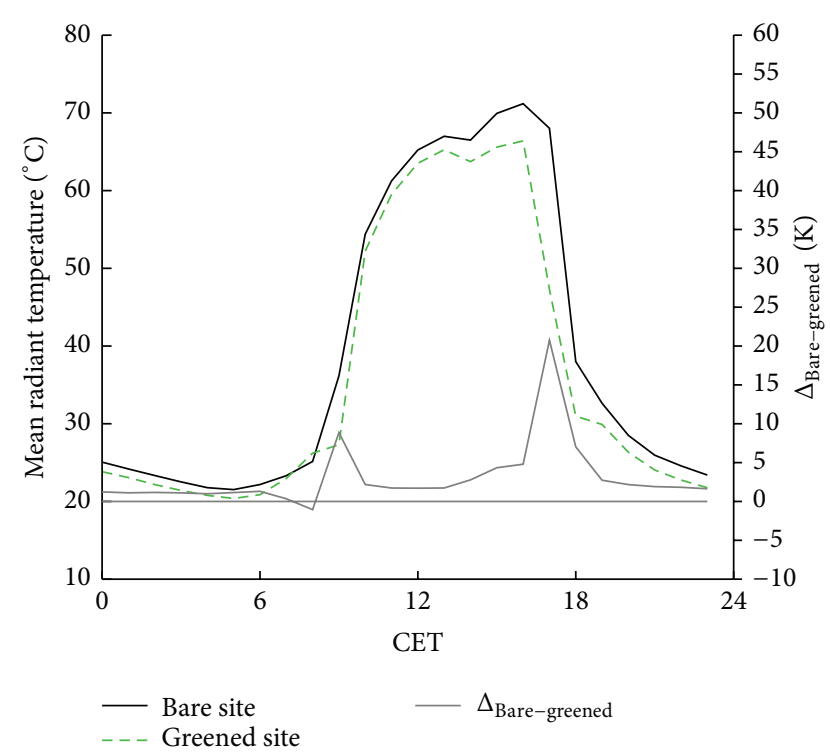

FIGURE 4: Mean radiant temperature observed at the bare and the greened site in front of the building on 7, 23, 2013.

\subsection{Evaluation of ENVI-met, RayMan, and SOLWEIG}

3.2.1. Mean Radiant Temperature. The models simulated $T_{\mathrm{mrt}}$ reasonably well in pattern and amplitude compared to the observations (Figures 6(a) and 6(b)). Experiments with SOLWEIG showed the lowest normalized standard deviation (Figure 6(b)) and high $r^{2}$ (Table 5). Despite high absolute errors in RMSD and MAD, experiments with ENVI-met produced the lowest MD (Table 5).

3.2.2. Long- and Short-Wave Radiation. Short-wave downward radiation in front of the greened and the bare site was simulated with high $r^{2}$ and low MD. RMSD showed larger deviation, especially in experiments with ENVI-met. Larger deviation also occurred in the morning and in the evening, which are the transition times between direct sun and shadow (Figure 7(a), Table 6). Simulated short-wave upward radiation differed much more from observations than short-wave
TABLE 5: Overview of the performance of the experiments (EXP) in simulating mean radiant temperature on $7,23,2013$, regarding root-mean-square deviation (RMSD), mean deviation (MD), mean absolute deviation (MAD), and coefficient of determination $\left(r^{2}\right)$.

\begin{tabular}{lcccc}
\hline \multicolumn{5}{c}{ Mean radiant temperature (K) } \\
EXP & RMSD & MD & MAD & $r^{2}$ \\
\hline E0a & 7.98 & -1.26 & 6.72 & 0.95 \\
E0 & 8.30 & 0.99 & 6.90 & 0.94 \\
E1 & 8.18 & 1.16 & 6.87 & 0.95 \\
R0 & 7.11 & -3.35 & 5.85 & 0.90 \\
R1 & 7.35 & -5.53 & 6.17 & 0.94 \\
S0 & 4.63 & -2.40 & 3.40 & 0.96 \\
S1 & 4.81 & -3.13 & 3.48 & 0.96 \\
Mean & 6.91 & -1.93 & 5.63 & 0.94 \\
\hline
\end{tabular}

downward radiation (Figure 7(b), Table 6). ENVI-met and SOLWEIG are able to compute short-wave upward radiation in contrast to RayMan. ENVI-met produced the amplitude more precisely than SOLWEIG, but SOLWEIG simulated the duration of intensive short-wave downward radiation closer to the observations (Figure 7(a)).

Concerning the long-wave downward radiation, SOLWEIG (S0 and S1) was the closest to the observations (Figures $7(\mathrm{c})$ and $7(\mathrm{~d})$ ). Long-wave upward radiation was underestimated during the night in all models. During the day, the differences between the simulations and observations decreased (Figure 7(c)).

3.2.3. Air Temperature and Specific Humidity. Simulations with RayMan and SOLWEIG are based on predefined air temperatures and specific humidity; only ENVI-met computes these variables itself. ENVI-met captured the diurnal cycle of air temperature, but specific humidity was reproduced with low deviations from observations only in the forced run (E1) (Figures 8(a) and 8(b)). E1 showed lower deviations than E0a and E0 in simulating air temperatures especially in the early morning (Figure 8(a), Table 7). E1 was the closest to the observation for specific humidity as well (Figure 8(b) and Table 7). The unforced experiments E0a and E0 overestimated specific humidity by $1.5 \mathrm{~g} / \mathrm{kg}$ (RMSD). 


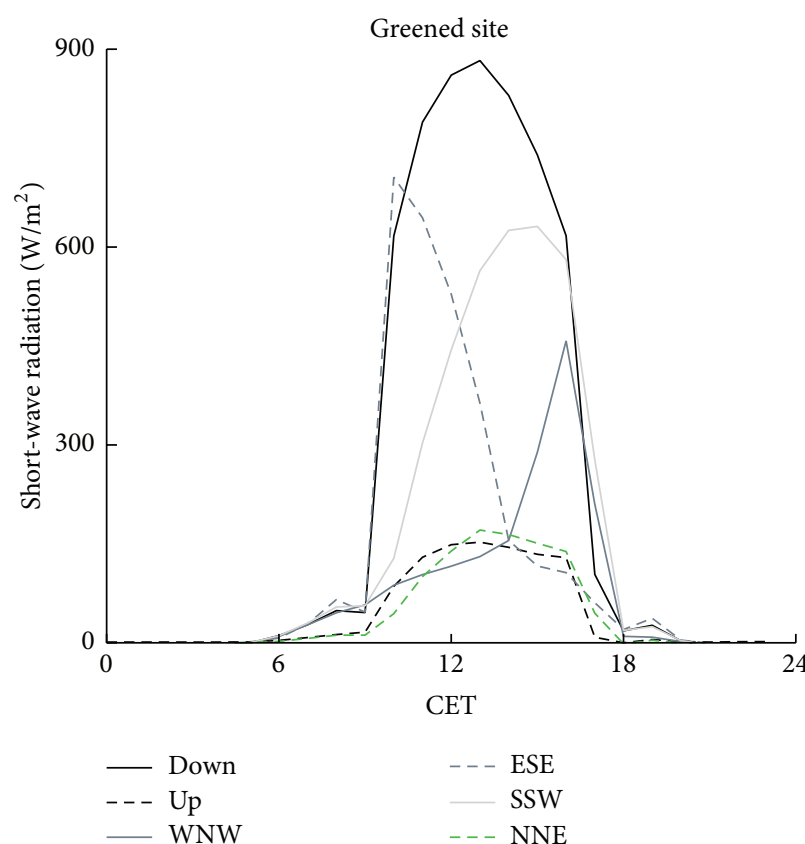

(a)

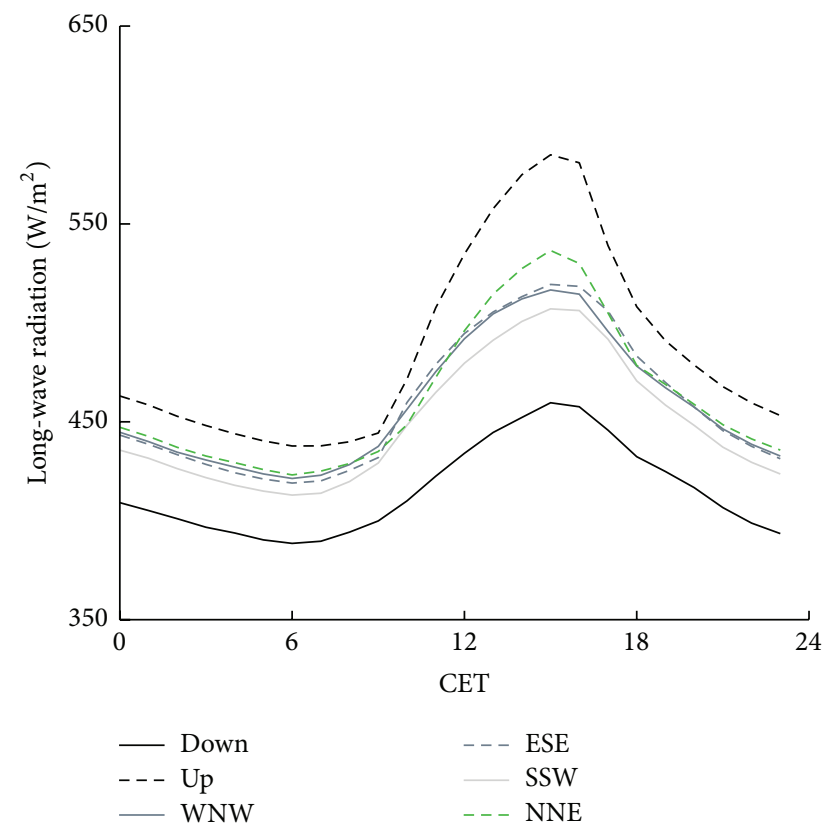

(c)

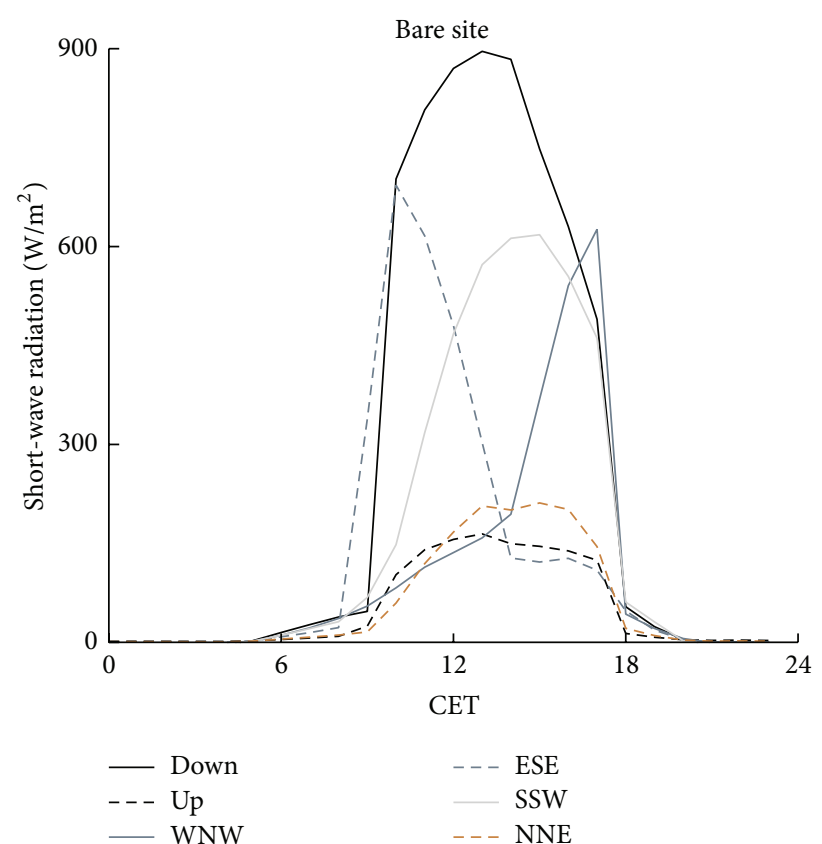

(b)

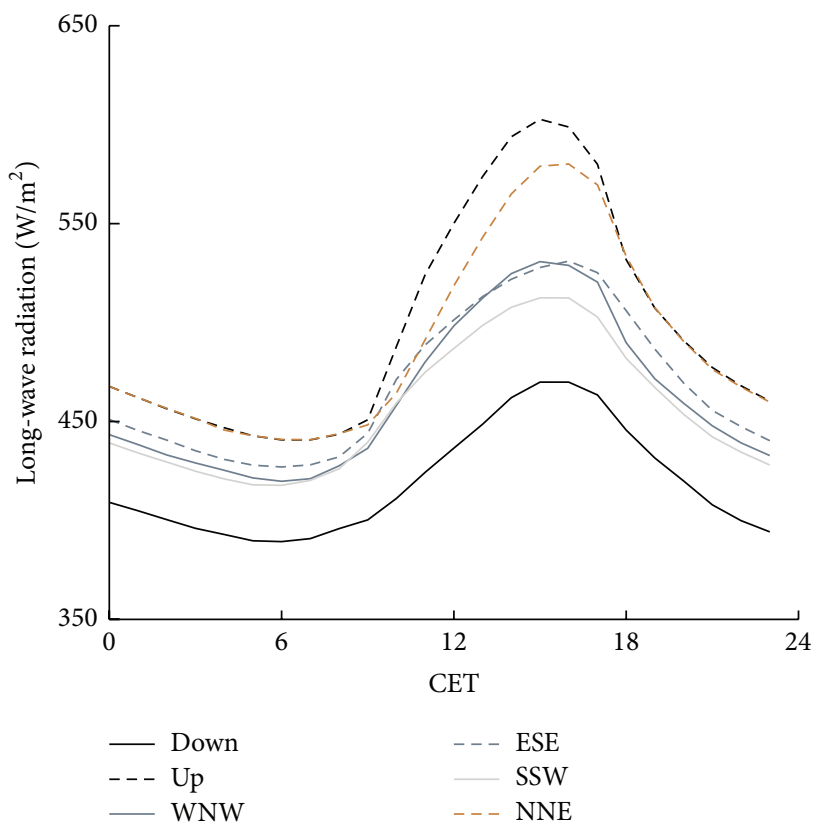

(d)

FIGURE 5: Short-wave radiation at the greened (a) and the bare (b) site and long-wave radiation at the greened (c) and the bare (d) site on $7,23,2013$. All components used to calculate mean radiant temperature are represented, which are up- and downward radiation (up, down) and radiation from the cardinal points (west-northwest (WNW), east-southeast (ESE), south-southwest (SSW), and north-northwest (NNE) (direction from the façades)).

3.3. Comparison of the Observed and Simulated Effects of Façade Greening. The observed differences between the bare and the greened site were not well reproduced by the models (Figure 9 and Table 8). The peaks in the transition times were simulated in all models to different extent. The cooling effect of façade greening, however, was only simulated by S0 and S1, although too small. The experiments with ENVI-met showed a higher $T_{\mathrm{mrt}}$ in front of the greened site than in front of the bare site, while R0 and R1 produced no differences between the sites (Table 8). Emitted long-wave radiation from 


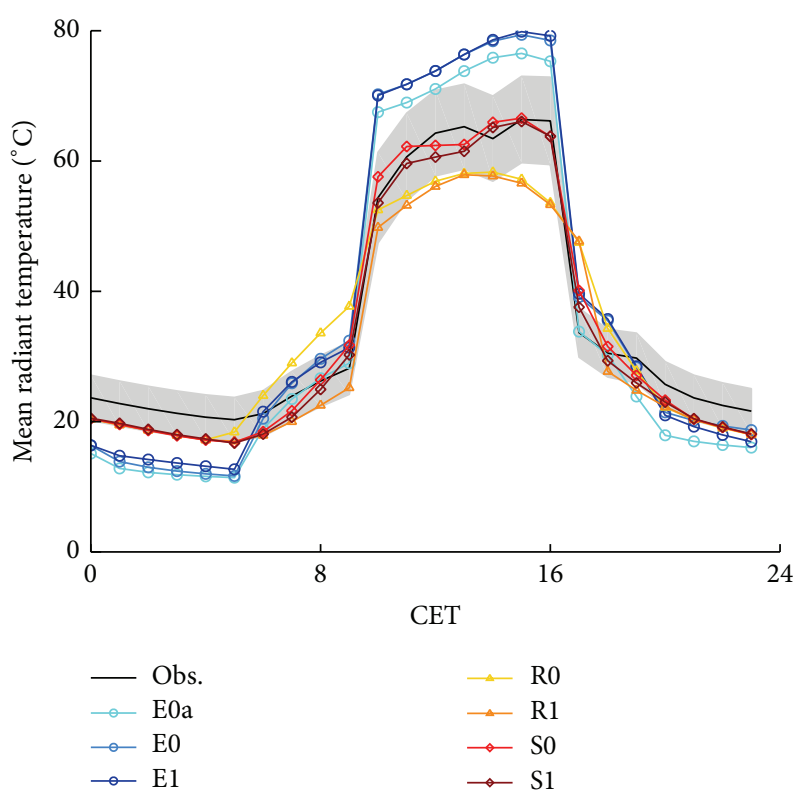

(a)

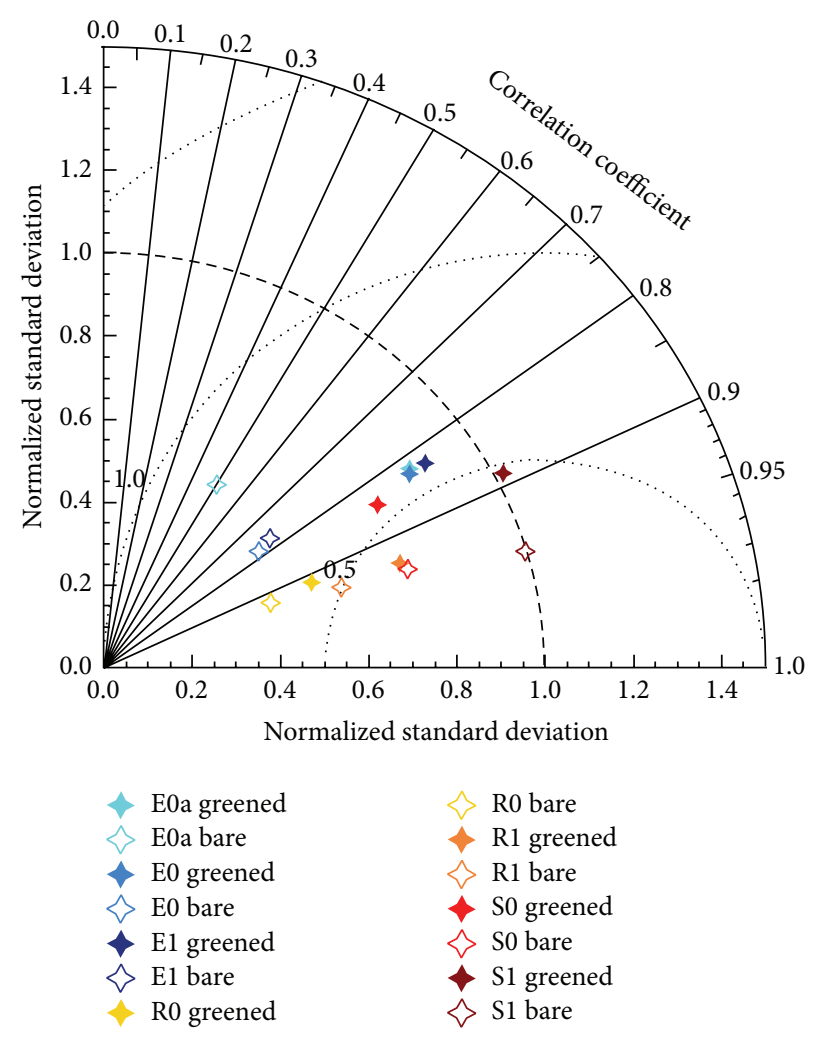

(b)

Figure 6: Mean radiant temperature on 7, 23, 2013, as observed and simulated (a) at the greened site and (b) Taylor-Diagram for the experiments with ENVI-met 3 (E0a), unforced (E0) and forced ENVI-met 4 (E1), RayMan without (R0) and with global radiation from observation (R1), and SOLWEIG without (S0) and with global radiation from observation (S1). The gray area indicates the accuracy range of the observations.

the greened site was reduced in the experiments with ENVImet and SOLWEIG (Figure 10(a)), but to a smaller extent (Figure 10(b)).

\section{Discussion}

4.1. Measuring the Effects of Façade Greening on $T_{\text {mrt }}$. The observed differences in $T_{\text {mrt }}$ of $2 \mathrm{~K}$ were distinct but lower than the measurement accuracy of about $4 \mathrm{~K}$. Tan et al. [15] detected larger differences of 2 to $13 \mathrm{~K}$ between sites with and without façade greening in a tropical environment. They only detected a reduction of $T_{\text {mrt }}$ when the façade greening was opposed to direct sunlight and not shaded [15]. In addition, the reduction depended on the distance to the façade and was mainly limited to $1 \mathrm{~m}$. Thus, the small observed differences in this study can be partly explained with the larger distance of the measurement to the façade of $1.2 \mathrm{~m}$. Furthermore, the effects of façade greening on air temperature were found to be small $(1.5 \mathrm{~K}$, Djedjig et al. [11], $1 \mathrm{~K}$, Berry et al. [16], $0.25 \mathrm{~K}$, Gross [14], and negligible, Pérez et al. [7]). In this case study façade greening was only attached to one façade wall. Hence, the impact on modified long- and short-wave radiation from the greened façade accounts to only $22 \%$ in calculating $T_{\mathrm{mrt}}(1)$. Therefore, the impact on $T_{\mathrm{mrt}}$ was limited, even though emitted long-wave radiation was clearly reduced in front of the greened façade. The albedo also interferes with $T_{\text {mrt }}$ because the light bare wall with its higher albedo reflected more short-wave radiation than the darker greened façade.

Furthermore, the differences in $T_{\mathrm{mrt}}$ cannot be reduced to the effects of façade greening exclusively. Boundary conditions were different between both sites regarding times of shadowing (Table 4). The opposing building structure is higher in front of the bare site than in front of the greened site (Figure 3), which leads to different shadowing times. In the evenings, at around $1700 \mathrm{CET}$, the greened façade was completely shadowed while the bare site still received direct sunlight for another half an hour. In the morning, at around $0900 \mathrm{CET}$, when the sunlight appeared at the façade, some differences existed as well. Furthermore, the opposing building might also have an influence regarding the reflection of short-wave radiation. With respect to short-wave and longwave radiation, the greened site received less energy from all directions than the bare one. Consequently, the cooling effect of $T_{\mathrm{mrt}}$ was overestimated in the observations. This demonstrates shortcomings in the case study as both sites were not identical regarding the radiation characteristics, which introduces uncertainties when interpreting deviations between the sites. The problem of comparability and usability of case studies to observe the effects of façade greening 


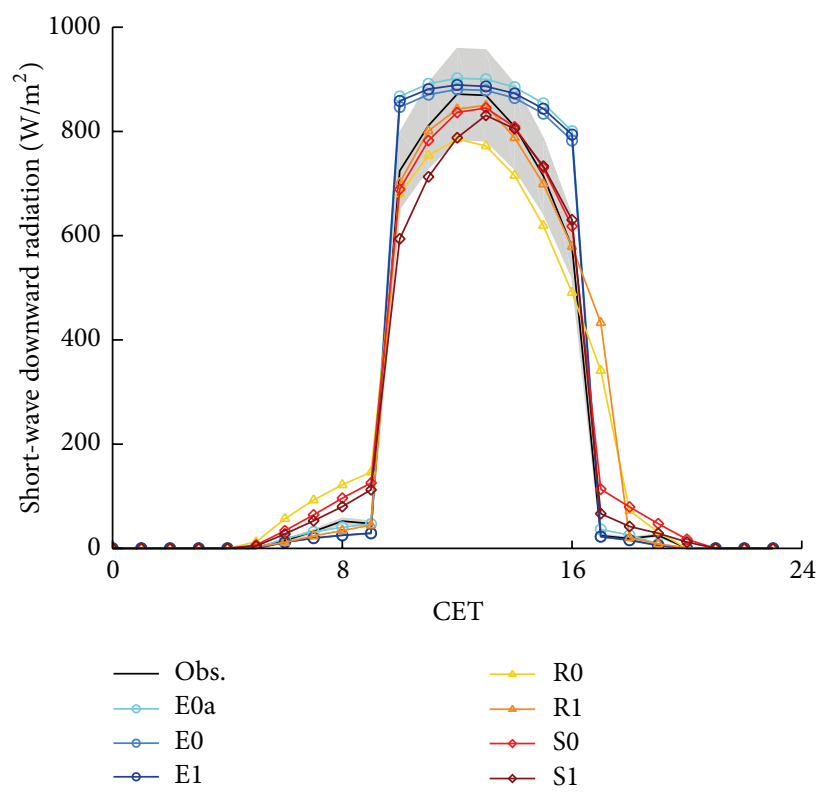

(a)

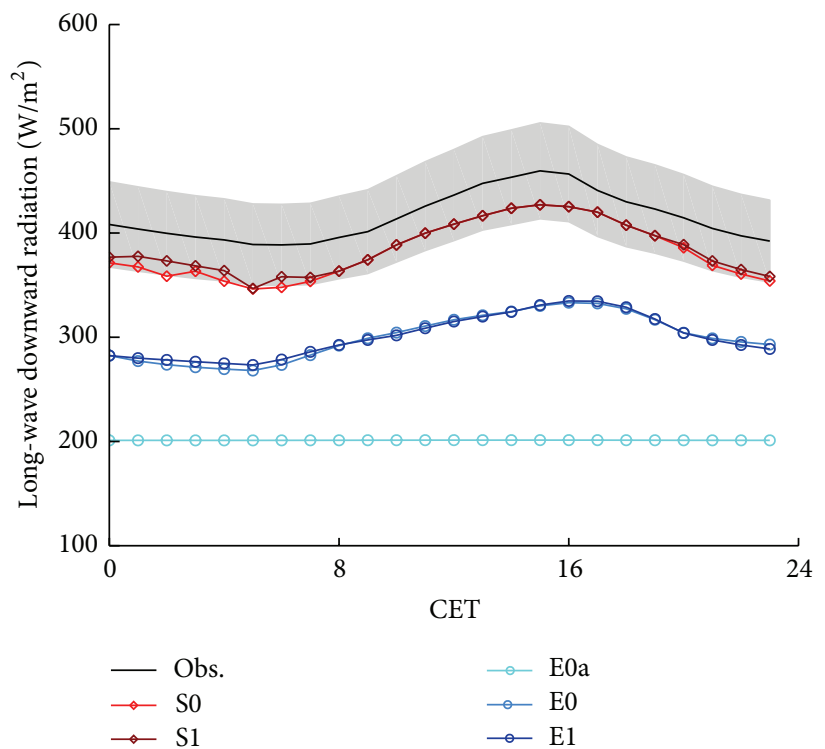

(c)

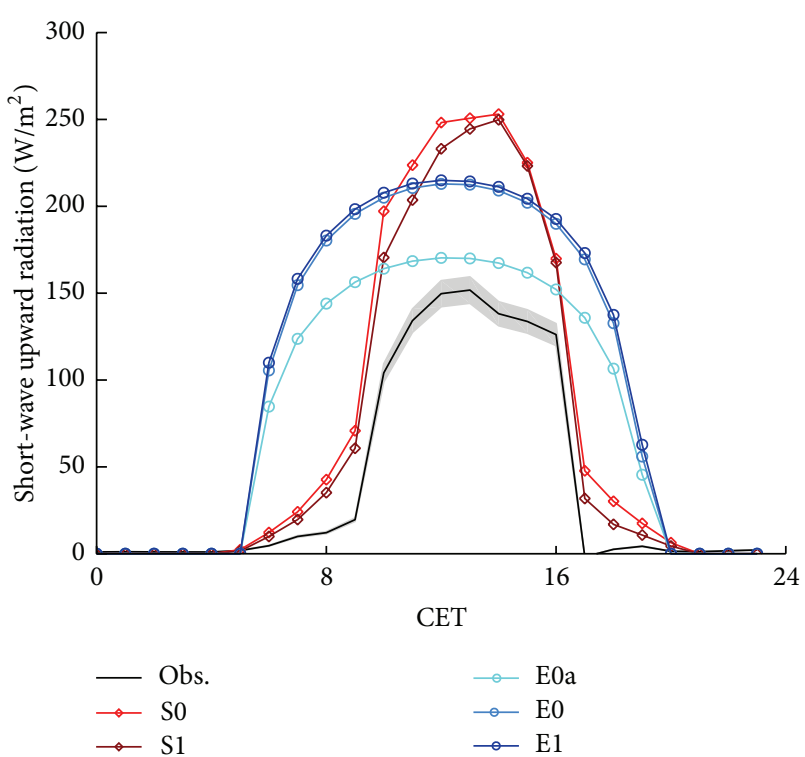

(b)

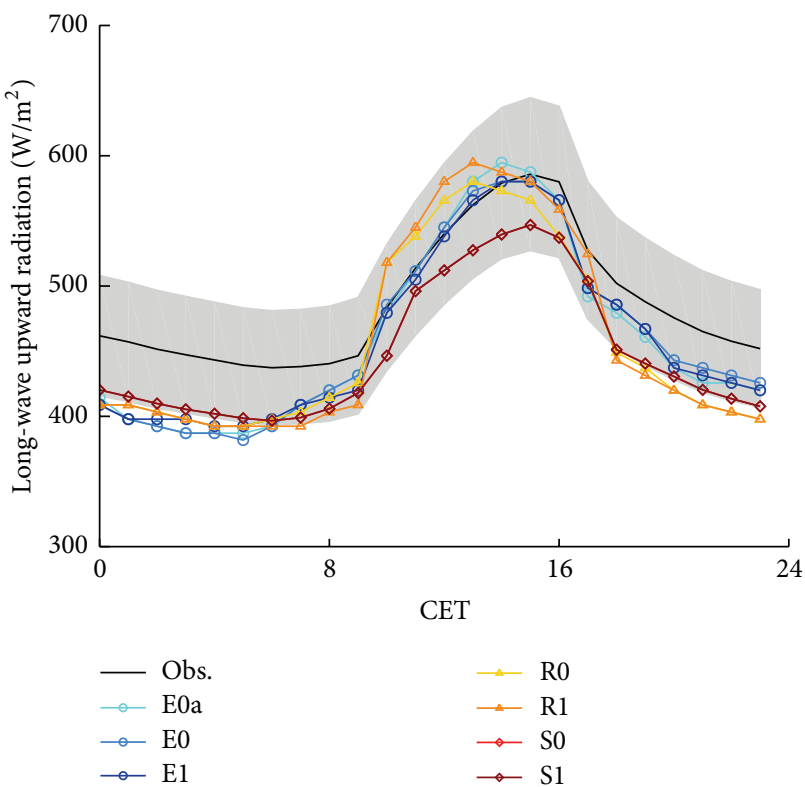

(d)

FIGURE 7: Comparison of simulated and observed (a) short-wave downward radiation, (b) short-wave upward radiation, (c) long-wave downward radiation, and (d) long-wave upward radiation on 7, 23, 2013, for the greened site in front of the façade simulated with ENVI-met 3 (E0a), unforced (E0) and forced ENVI-met 4 (E1), RayMan without (R0) and with global radiation from observation (R1), and SOLWEIG without (S0) and with global radiation from observation (S1). The gray areas indicate the accuracy range of the observations.

occurs often as criticized by Hunter et al. [10]. Specifically in complex urban environments optimal study sites are difficult to find. Elaborated assessments (e.g., integral radiation measurements) can reveal such problems in contrast to simple single-variable measurements (e.g., air temperature). Our findings further support the need of reliable model tools in combination with observations to study the effects of façade greening for specific sites and climates.

\subsection{Evaluation of ENVI-met, RayMan, and SOLWEIG}

4.2.1. Mean Radiant Temperature. Simulated $T_{\mathrm{mrt}}$ deviated about $7 \mathrm{~K}$ (mean RMSD) from the observation in this and about MD 2-8 K and 2-15 K RMSD in former studies (Table 9). This uncertainty range is reasonable compared to the average accuracy in measurements of about $4 \mathrm{~K}$. The uncertainty, however, varies largely depending on 
TABLE 6: Overview of the performance in simulating downward (a) and upward (b) short-wave and long-wave radiation on 7, 23, 2013. For further explanations refer to Table 5.

(a)

\begin{tabular}{lcccc}
\hline \multicolumn{5}{l}{ Short-wave downward radiation $\left(\mathrm{W} / \mathrm{m}^{2}\right)$} \\
EXP & RMSD & MD & MAD & $r^{2}$ \\
\hline E0a & 130.46 & 46.31 & 50.33 & 0.91 \\
E0 & 124.44 & 36.96 & 47.12 & 0.91 \\
E1 & 128.17 & 40.46 & 49.70 & 0.91 \\
R0 & 82.33 & -6.15 & 54.06 & 0.96 \\
R1 & 70.50 & 3.19 & 25.59 & 0.96 \\
S0 & 54.65 & -3.20 & 29.36 & 0.98 \\
S1 & 65.86 & -16.86 & 34.64 & 0.97 \\
Mean & 93.77 & 14.39 & 41.54 & 0.94 \\
\hline & Long-wave downward radiation $\left(\mathrm{W} / \mathrm{m}^{2}\right)$ & \\
EXP & RMSD & MD & MAD & $r^{2}$ \\
\hline E0a & 209.60 & -208.03 & 208.03 & 0.01 \\
E0 & 116.32 & -115.83 & 115.83 & 0.82 \\
E1 & 115.27 & -114.85 & 114.85 & 0.86 \\
R0 & - & - & - & - \\
R1 & - & - & - & - \\
S0 & 34.89 & -34.31 & 34.31 & 0.95 \\
S1 & 31.66 & -31.16 & 31.16 & 0.95 \\
Mean & 101.44 & -100.71 & 100.71 & 0.71 \\
\hline
\end{tabular}

(b)

\begin{tabular}{lcccc}
\hline \multicolumn{5}{c}{ Short-wave upward radiation $\left(\mathrm{W} / \mathrm{m}^{2}\right)$} \\
EXP & RMSD & MD & MAD & $r^{2}$ \\
\hline E0a & 61.86 & 38.34 & 39.84 & 0.60 \\
E0 & 84.76 & 58.55 & 60.04 & 0.60 \\
E1 & 87.12 & 60.50 & 62.00 & 0.60 \\
R0 & - & - & - & - \\
R1 & - & - & - & - \\
S0 & 56.55 & 32.74 & 35.11 & 0.95 \\
S1 & 51.36 & 27.94 & 30.57 & 0.95 \\
Mean & 68.33 & 43.61 & 45.51 & 0.74 \\
\hline & Long-wave upward radiation $\left(\mathrm{W} / \mathrm{m}^{2}\right)$ & \\
EXP & RMSD & MD & MAD & $r^{2}$ \\
\hline E0a & 35.19 & -26.89 & 30.96 & 0.91 \\
E0 & 33.28 & -23.81 & 27.62 & 0.92 \\
E1 & 31.70 & -24.88 & 27.19 & 0.93 \\
R0 & 46.23 & -35.65 & 42.69 & 0.83 \\
R1 & 46.62 & -33.10 & 43.46 & 0.86 \\
S0 & 43.28 & -42.09 & 42.09 & 0.97 \\
S1 & 43.30 & -42.12 & 42.12 & 0.97 \\
Mean & 39.94 & -32.65 & 36.59 & 0.91 \\
\hline
\end{tabular}

the selected model and study design (Table 9). Krüger et al. [20] concluded for RayMan that the uncertainty in calculating $T_{\text {mrt }}$ depends on different factors, such as morphology, meteorological conditions, and surface properties. For example, correlation coefficients were much higher in this
TABLE 7: Overview of ENVI-met's performance in simulating air temperatures and specific humidity on 7, 23, 2013. For further explanations refer to Table 5 .

\begin{tabular}{lcccc}
\hline EXP & RMSD & MD & MAD & $r^{2}$ \\
\hline \multicolumn{5}{c}{ Air temperature (K) } \\
E0a & 1.39 & 0.00 & 1.13 & 0.87 \\
E0 & 1.68 & 0.06 & 1.43 & 0.83 \\
E1 & 0.96 & 0.40 & 0.86 & 0.98 \\
Mean & 1.35 & 0.16 & 1.14 & 0.89 \\
\hline \multicolumn{5}{c}{ Specific humidity $(\mathrm{g} / \mathrm{kg})$} \\
E0a & 1.44 & 1.17 & 1.31 & 0.10 \\
E0 & 1.54 & 1.28 & 1.40 & 0.10 \\
E1 & 0.35 & -0.03 & 0.25 & 0.91 \\
Mean & 1.11 & 0.81 & 0.99 & 0.37 \\
\hline
\end{tabular}

TABLE 8: Mean ( \pm standard deviation), minimum and maximum difference in $T_{\text {mrt }}$ between bare and greened site in observation (OBS) on 7, 23, 2013 (10-16 CET) and experiments (EXP) with ENVI-met 3 (E0a), ENVI-met 4 (E0 and E1), RayMan (R0 and R1) and SOLWEIG (S0 and S1).

\begin{tabular}{lccc}
\hline EXP & \multicolumn{3}{c}{$T_{\text {mrt }}($ Bare - Greened $)(\mathrm{K})$} \\
Mean & Mininum & Maximum \\
\hline OBS & $2.13 \pm 1.81$ & 0.02 & 5.02 \\
E0a & $-2.81 \pm 2.25$ & -5.89 & 0.57 \\
E0 & $-4.14 \pm 1.41$ & -5.56 & -1.82 \\
E1 & $-4.32 \pm 1.44$ & -5.42 & -1.88 \\
R0 & $0.01 \pm 0.04$ & 0.00 & 0.10 \\
R1 & $-0.09 \pm 0.07$ & -0.20 & 0.00 \\
S0 & $0.96 \pm 0.88$ & -0.57 & 1.94 \\
S1 & $1.30 \pm 1.01$ & -0.49 & 2.28 \\
\hline
\end{tabular}

study compared to the investigations of Chen et al. [17]. Such deviations are caused by model specific parameterizations.

Other reasons for deviations in all applied models were discrepancies in building or plant shapes. All experiments produced larger deviations during the transition between shadow and direct radiation, which was also reported by Thorsson et al. [4] and Matzarakis et al. [23]. Such deviations are caused by inaccuracies in building shapes due to the spatial resolution of $1 \mathrm{~m}$ or by errors in the basic data of building shapes.

Simulated $T_{\text {mrt }}$ differed hardly between the computed and predefined meteorological input data. Consequently, calculated global radiation by RayMan and SOLWEIG was sufficient for simulating $T_{\mathrm{mrt}}$, and observations of global radiations did not enhance the model performance considerably, at least for this nearly cloud-free day. In ENVI-met, the forcing of air temperature and relative humidity showed only minor effects on simulating $T_{\text {mrt }}$ as well.

In SOLWEIG, the transmissivity is of importance for calculating $T_{\mathrm{mrt}}$ beneath vegetation [25]. We applied an averaged value for the whole model domain because we measured transmissivity only at two points of the façade greening and SOLWEIG does not allow any spatial variations. Nevertheless, the range of deviations in this study is similar 


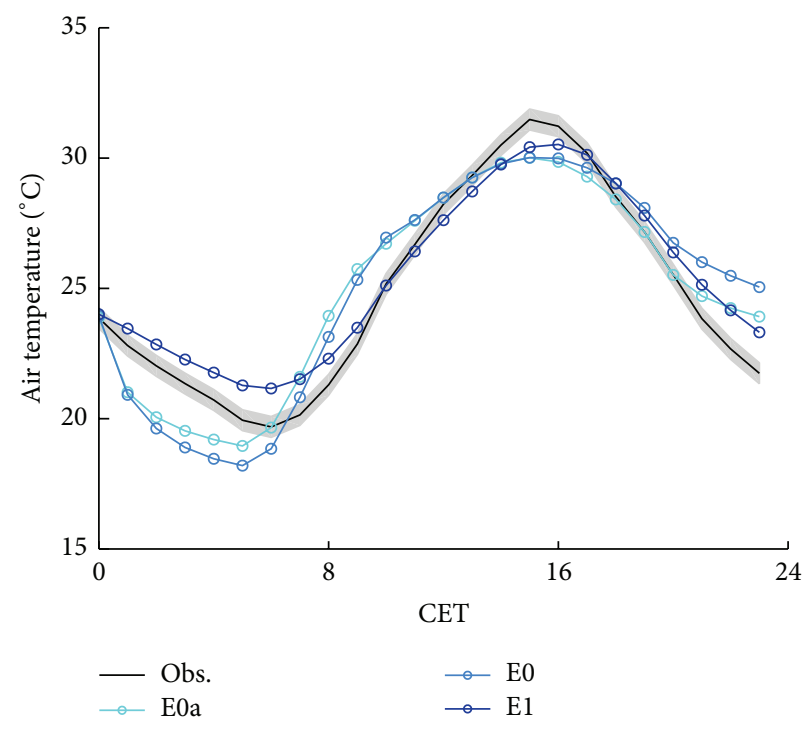

(a)

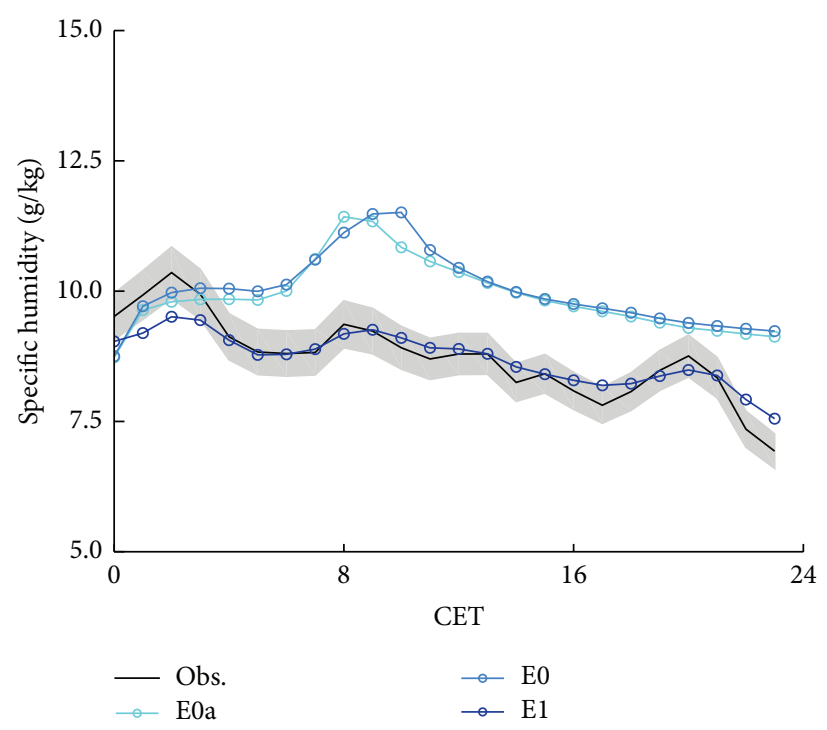

(b)

FIGURE 8: Comparison of simulated and observed (a) air temperatures and (b) specific humidity of the experiments with ENVI-met 3 (E0a) and unforced and forced ENVI-met 4 (E0 and E1) on 7, 23, 2013. The gray area indicates the accuracy range of the observations.

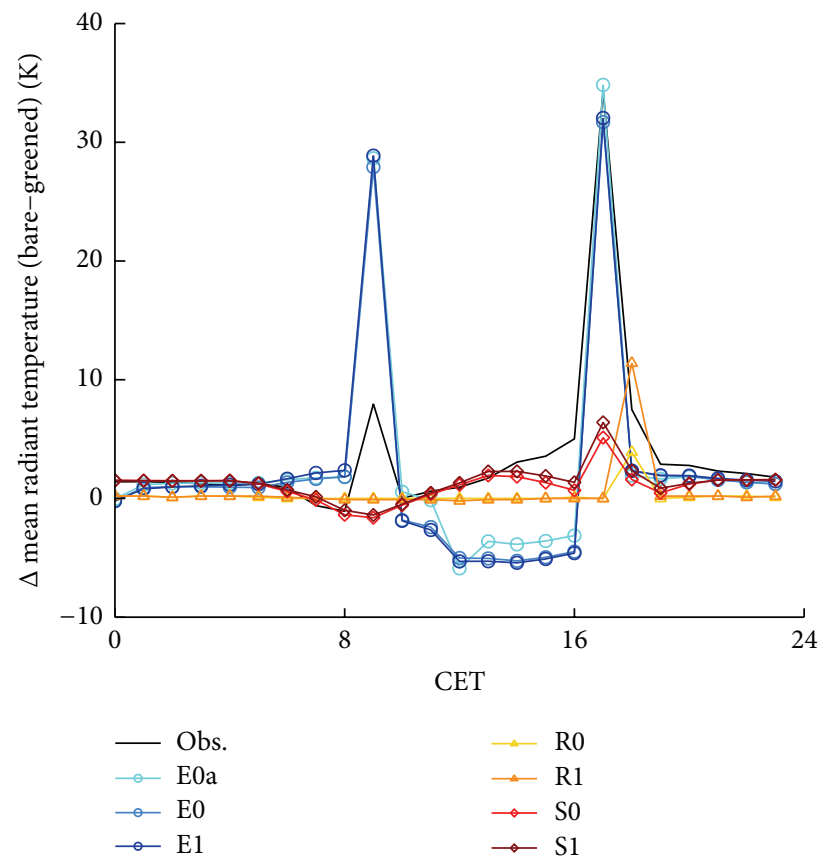

FIGURE 9: Differences between the bare and greened site in observation and simulations $(7,23,2013)$ in experiments with ENVImet 3 (E0a), unforced (E0) and forced ENVI-met 4 (E1), RayMan without (R0) and with global radiation from observation (R1), and SOLWEIG without (S0) and with global radiation from observation (S1).

to findings by Lindberg and Grimmond [25], who detected a RMSD of $3.1 \mathrm{~K}$ and a MAD of $2.74 \mathrm{~K}$.

RayMan underestimated $T_{\mathrm{mrt}}$ in this study probably as a consequence of too low short-wave downward radiation. On
TABle 9: Overview of deviations in mean radiant temperature between simulations and observations in other studies concerning root-mean-square deviation (RMSD), mean deviation (MD), mean absolute deviation (MAD), and coefficient of determination $\left(r^{2}\right)$. Standard deviations $( \pm)$ are stated, if more than one analysis is performed per study.

\begin{tabular}{lcccc}
\hline \multicolumn{5}{c}{ Mean radiant temperature (K) } \\
Reference & RMSD & MD & MAD & $r^{2}$ \\
\hline \multicolumn{5}{c}{ ENVI-met } \\
{$[17]$} & - & - & - & $0.09 \pm 0.1$ \\
{$[18]$} & $4.13 \pm 0.4$ & - & - & - \\
E1 & 8.18 & 1.16 & 6.87 & 0.95 \\
\hline \multicolumn{5}{c}{ RayMan } \\
{$[17]$} & - & - & - & $0.82 \pm 0.0$ \\
{$[19]$} & - & - & - & 0.88 \\
{$[20]$} & $14.93 \pm 3.5$ & - & $12.88 \pm 3.5$ & $0.37 \pm 0.2$ \\
{$[21]$} & - & - & - & 0.85 \\
{$[4]$} & - & $8.45 \pm 1.7$ & - & - \\
{$[22]$} & - & - & - & 0.77 \\
{$[23]$} & $1.7 \pm 0.5$ & - & - & $0.96 \pm 0.5$ \\
Mean & $8.32 \pm 2.0$ & $8.45 \pm 1.7$ & $12.88 \pm 3.5$ & $0.74 \pm 0.23$ \\
R1 & 7.35 & -5.53 & 6.17 & 0.94 \\
\hline \multicolumn{5}{c}{ SOLWEIG } \\
{$[17]$} & - & - & - & 0.32 \\
{$[24]$} & 4.8 & $2.00 \pm 0.3$ & - & 0.94 \\
{$[25]$} & 3.1 & - & 2.74 & 0.91 \\
Mean & 3.95 & $2.00 \pm 0.3$ & 2.74 & 0.72 \\
S1 & 4.81 & -3.13 & 3.48 & 0.96 \\
\hline & \multicolumn{5}{c}{}
\end{tabular}

the contrary, Krüger et al. [20] examined an overestimation for various cloudiness conditions (RMSD 14.93 K, MAD 


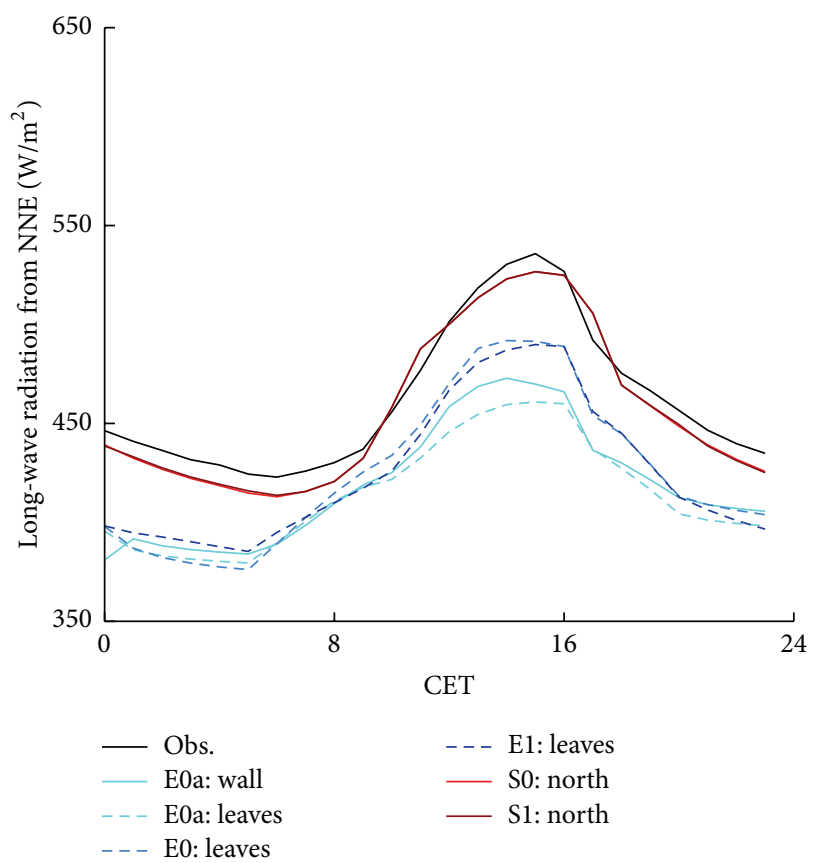

(a)

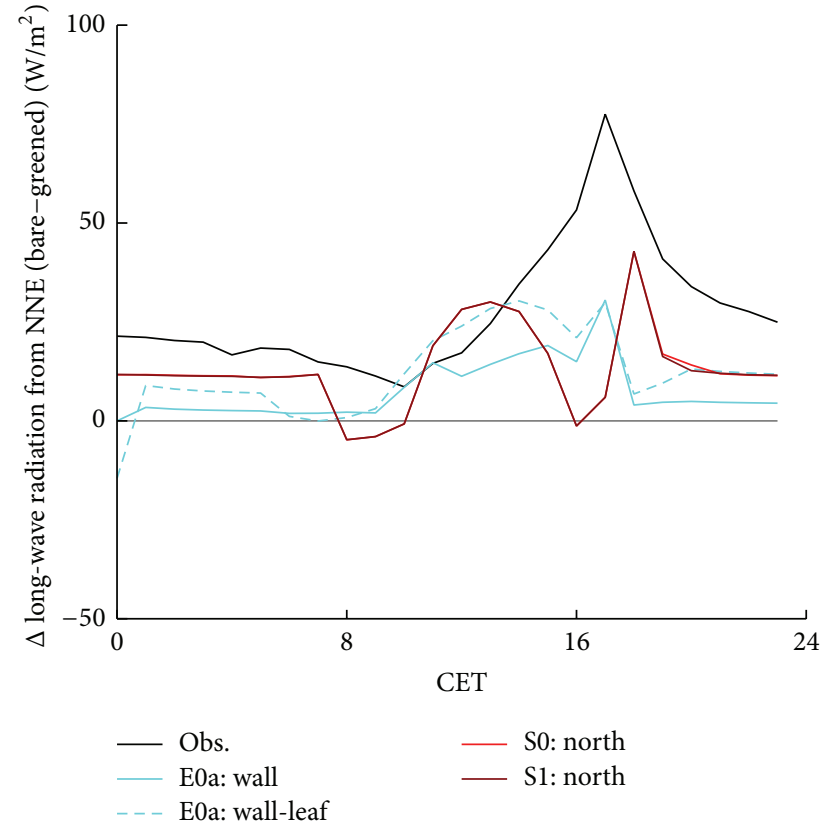

(b)

FIGURE 10: Simulated long-wave radiation (a) emitted from the greened site (wall or leaves) and (b) differences between bare and greened façade in simulations and observation for the experiments with ENVI-met 3 (E0a), unforced (E0) and forced ENVI-met 4 (E1), and SOLWEIG without (S0) and with global radiation from observation $(\mathrm{S} 1)(7,23,2014)$.

$12.88 \mathrm{~K})$. Additionally, they detected a higher agreement with observations on clear sunny days compared to cloudy ones [20]. During sunny days the accuracy of SVF has a high influence on the uncertainty in simulating $T_{\mathrm{mrt}}[20]$. Hence, inaccuracies in the building and vegetation shape had a large impact in this study. The deviation in RayMan varies remarkably in this study and other ones $[4,19,22]$ (Table 9).

The uncertainty also differs strongly between different studies with ENVI-met. Ali-Toudert [43] detected an underestimation of $T_{\mathrm{mrt}}$ during the day and an overestimation during the night. In this study, however, the overestimation of short-wave radiation led to an overestimation of $T_{\mathrm{mrt}}$. Yang et al. [44] also detected an overestimation in ENVI-met due to an overestimation of short-wave downward radiation (without statistical values).

Overall, SOLWEIG simulated $T_{\text {mrt }}$ closest to the observation both in this study and in former ones (Table 9). ENVImet showed the largest deviations in this study. Furthermore, shortcomings in the evaluation of all three models become visible regarding the amount of studies and in comparability due to different statistics to evaluate models uncertainty.

4.2.2. Long- and Short-Wave Radiation. Short-wave downward radiation showed less deviations compared to other radiation components. ENVI-met did not capture the amplitude of global radiation well, partly because only water vapor alternates short-wave radiation [44]. Additionally, AliToudert [43] detected problems in simulating global radiation with ENVI-met and consequently a radiation adjustment factor was introduced to ENVI-met. Here, short-wave downward radiation in ENVI-met was reduced in advance by $25 \%$ to match the amplitude of observations (Table 2). Additional deviations in short-wave downward radiation were produced by the resolution of grid points and by inaccuracies of the input data of buildings and vegetation as discussed for $T_{\mathrm{mrt}}$. The small deviation in short-wave downward radiation was a main driver for the sufficient simulation of $T_{\mathrm{mrt}}$.

Short-wave upward radiation has less impact on $T_{\mathrm{mrt}}$ due to the generally smaller energy flux density and low $F_{i}$ in the calculation of $T_{\text {mrt }}$. Thus, the overestimation in all experiments was less decisive for simulating $T_{\mathrm{mrt}}$. ENVI-met overestimated the duration of intense shortwave upward radiation because shadowing effects of the surface are neglected. SOLWEIG captured the duration but overestimated the amplitude of short-wave upward radiation due to a higher albedo. SOLWEIG cannot consider different albedo values of ground surfaces and walls. In future, this problem might be fixed because Lindberg and Grimmond [25] proposed for the next SOLWEIG version the possibility to specify albedo and emissivity spatially.

Long-wave downward radiation was underestimated. The overestimations of short-wave upward radiation and longwave downward radiation compensate each other and thus the total impact of the inaccuracies on $T_{\text {mrt }}$ was reduced. ENVI-met 3 (E0a) failed to simulate the diurnal variation of long-wave downward radiation as it uses averaged emissivity values and surface temperatures to calculate it.

Long-wave upward is underestimated during the night because the models do not consider heat storage of 
the buildings sufficiently (ENVI-met 4) or not at all (ENVImet 3, SOLWEIG, and RayMan). Hwang et al. [19] and Lin et al. [21] discussed these shortcomings in ENVI-met 3 and detected the fact that daytime surface temperature was overestimated and nighttime surface temperature was underestimated. ENVI-met 4 should be able to consider these effects in principle but failed in this case study. Possibly, the heat storage was insufficiently parameterized or the spin-up time was too short. Follow-up studies might acquire a more suitable description of heat storage in the walls. During the night, the underestimation of emitted long-wave radiation also led to undervalued $T_{\text {mrt }}$ in all experiments.

Overall, the individual terms of the radiation balance were, with the exception of short-wave downward radiation, not plausibly simulated by all models. Short-wave downward radiation may also show much higher inaccuracies under cloudy conditions as Krüger et al. [20] detected for RayMan. Furthermore, the lack of model evaluation is more apparent for the individual terms of the radiation balance than for $T_{\mathrm{mrt}}$ as we detected only three other studies (Table 10), which leads to a high uncertainty regarding the reliability in simulating these variables.

4.2.3. Air Temperature and Specific Humidity. ENVI-met reproduced air temperature close to the observations with a RMSD between 0.9 and $1.6 \mathrm{~K}$ and MD between 0.0 and $0.4 \mathrm{~K}$ in this case study and with a mean RMSD of $1.9 \mathrm{~K}$ and MD $-0.65 \mathrm{~K}$ in former studies (Table 11). During the day, ENVImet tended to underestimate air temperature but overestimated it during the night [21, 43]. Berkovic et al. [45], who compared simulations and observations qualitatively, found larger differences during the evenings for air temperatures and relative humidity (about $3 \mathrm{~K}, 15 \%$ ). Forcing in E1 clearly decreased the uncertainty compared to E0 especially during the day but showed only minor effects on $T_{\mathrm{mrt}}$.

The uncertainty in simulating air temperature with ENVI-met varies between different studies remarkably (Table 11). A high agreement was achieved by Skelhorn et al. [35] and Srivanit and Hokao [26] after optimization and calibration efforts of different parameters and with a longer spin-up time. Air temperature has been evaluated in several studies. Thus, the simulation seems to be reliable, with an uncertainty of about $1.88 \mathrm{~K}$ (RMSD).

Specific humidity was evaluated by Chen et al. [17] with a RMSD of $0.82 \mathrm{~g} / \mathrm{kg}$, which is higher than in this study $(\mathrm{RMSD}=0.35 \mathrm{~g} / \mathrm{kg})$. Forcing (E1) improved the simulation of specific humidity compared to the unforced runs (E0a, E0).

4.3. Comparison of the Observed and Simulated Effects of Façade Greening. The applied models were not able to reproduce the observed effects of façade greening. SOLWEIG was the only model that simulated at least a small reduction of $T_{\mathrm{mrt}}$. The reductions cannot be related to transpirative effects of the plants because such effects are not considered in SOLWEIG. Thus, the decrease in $T_{\text {mrt }}$ was produced by radiation changes. Simulated long-wave radiation emitted from the wall was clearly reduced in front of the façade greening (S0, S1).
TABLE 10: Overview of deviations in short-wave downward radiation between simulation and observation in other studies. For further explanation refer to Table 9.

\begin{tabular}{lcccc}
\hline \multirow{5}{*}{ Short-wave downward radiation $\left(\mathrm{W} / \mathrm{m}^{2}\right)$} \\
Reference & RMSD & MD & MAD & $r^{2}$ \\
\hline & & ENVI-met & \\
{$[26]$} & - & $-289.15 \pm 8.8$ & - & - \\
E1 & 128.17 & 40.46 & 49.70 & 0.91 \\
\hline & \multicolumn{5}{c}{} \\
{$[24]$} & 42.1 & SOLWEIG & - & 0.97 \\
{$[25]$} & 43.3 & - & - & 0.97 \\
Mean & 42.2 & - & - & 0.97 \\
S1 & 65.86 & -16.86 & 34.64 & 0.97 \\
\hline
\end{tabular}

TABLE 11: Overview of deviations in air temperature and specific humidity between simulation and observation in other studies. For further explanations refer to Table 9.

\begin{tabular}{lcccc}
\hline \multicolumn{5}{c}{ Air temperature (K) } \\
Reference & RMSD & MD & MAD & $r^{2}$ \\
\hline$[27]$ & $2.79 \pm 0.0$ & $0.66 \pm 0.1$ & $2.40 \pm 0.1$ & $0.70 \pm 0.0$ \\
{$[28]$} & $1.45 \pm 0.1$ & $-1.29 \pm 0.0$ & $1.29 \pm 0.0$ & - \\
{$[29]$} & $1.95 \pm 0.4$ & - & - & - \\
{$[30]$} & $2.91 \pm 0.9$ & $-0.62 \pm 1.3$ & $2.45 \pm 0.7$ & $0.90 \pm 0.1$ \\
{$[18]$} & $1.37 \pm 0.4$ & - & - & - \\
{$[31]$} & $1.74 \pm 0.3$ & - & - & - \\
{$[32]$} & - & - & - & 0.97 \\
{$[33]$} & - & - & - & $0.70 \pm 0.1$ \\
{$[34]$} & - & $-3.50 \pm 0.5$ & - & $0.95 \pm 0.0$ \\
{$[35]$} & - & $0.64 \pm 0.3$ & - & 0.94 \\
{$[26]$} & - & $-0.56 \pm 0.9$ & - & - \\
{$[26]$} & - & 0.10 & - & - \\
{$[36]$} & $0.93 \pm 0.1$ & - & - & $0.95 \pm 0.0$ \\
Mean & $1.88 \pm 0.4$ & $-0.65 \pm 0.53$ & $2.05 \pm 0.3$ & $0.87 \pm 0.4$ \\
E1 & 0.96 & 0.40 & 0.86 & 0.98 \\
\hline \multicolumn{5}{c}{ Specific humidity $(\mathrm{g} / \mathrm{kg})$} \\
{$[36]$} & $0.82 \pm 0.0$ & - & - & $0.54 \pm 0.0$ \\
E1 & 0.35 & -0.03 & 0.25 & 0.91 \\
\hline
\end{tabular}

ENVI-met, which is able to simulate transpiration, reproduced higher $T_{\mathrm{mrt}}$ in front of the greened site compared to the bare site. Emitted long-wave radiation was reduced in front of the greened façade, but the effect was not permeated to $T_{\mathrm{mrt}}$. Increasing the spin-up time in ENVI-met might amplify the generation of effects of façade greening. Specifically in ENVImet and RayMan, the inabilities in simulating a reduction of $T_{\mathrm{mrt}}$ in front of the greened façade could not be easily traced back because they do not return all relevant components for $T_{\mathrm{mrt}}$.

To conclude, the models showed a limited applicability to façade greening in this study. The small alterations of longand short-wave radiation due to façade greening were indistinct. Thus, specific types of urban green cannot be included 
in these models without further adaptations. Restrictions must be made, however, regarding the complex real-case study site. Moreover, modification of model parameters and settings (e.g., spin-up time) especially for ENVI-met could lead to other results but would go beyond the scope of this study.

\section{Conclusions}

The effect of façade greening on outdoor human bioclimate was limited in this case study because only a small reduction $T_{\text {mrt }}$ in front of the façade greening was detected. Hence, façade greening has only a minor effect in reducing outdoor heat stress. With a façade greening attached to more than one façade in a street canyon or court yard the effect on $T_{\mathrm{mrt}}$, however, might be enlarged.

The general ability of ENVI-met, RayMan, and SOLWEIG to simulate $T_{\mathrm{mrt}}$ was reasonable as expected for well-established models. Nevertheless, the deviations from observations vary largely between different studies. Additionally, the deviations from observations for other variables (specific humidity, long-wave downward or short-wave upward radiation) were higher and might impede the models' ability in assessing heat stress. When considering the large differences in complexity and computational time, the good performance of the simple SOLWEIG and RayMan models contrary to the elaborate ENVI-met model is encouraging. ENVI-met, however, offers more opportunities for various issues, such as studies of plant-air interactions or effects of changes in albedo of individual surfaces. It also provides more options for tuning and modifications by the users, which were not completely exhausted in this study. Moreover, we recognized a lack of model evaluations regarding the amount of evaluation studies and the considered variables. An explicit statement of model uncertainties for interpreting the results should be included in every study and not only in rare exceptional cases.

The applied models are helpful for assessing human bioclimate in general due to the acceptable uncertainty in simulating $T_{\mathrm{mrt}}$. In the specific case of façade greening in a complex urban environment, however, their usability is limited in the current set-up. Generic studies or simple environments combined with modified parameterizations might improve the usability. Specific types of vegetation besides trees should not be incorporated in these models without modifications and extensive evaluation. Therefore, new simulation tools or advancements in existing models are desirable to complement observational case studies. The combination of biometeorological microclimate models and observations is helpful in order to complement benefits of each method. More effort in bridging the gaps between case studies and large-scale applications of countermeasures is needed to detect an effective countermeasure against heat stress risks in cities.

\section{Conflict of Interests}

The authors declare that there is no conflict of interests regarding the publication of this paper.

\section{Acknowledgments}

The authors wish to thank their colleagues for the great support during the measurement campaign and the enriching discussions. The study is part of the Research Unit 1736 "Urban Climate and Heat Stress in Mid-Latitude Cities in View of Climate Change (UCaHS)" (http://www.UCaHS .org) funded by the Deutsche Forschungsgemeinschaft (DFG) under the codes SCHE 750/8-1, SCHE 750/9-1, and WE 1125/30-1.

\section{References}

[1] D. Scherer, U. Fehrenbach, T. Lakes, S. Lauf, F. Meier, and C. Schuster, "Quantification of heat-stress related mortality hazard, vulnerability and risk in Berlin, Germany," Die Erde, vol. 144, no. 3-4, pp. 238-259, 2013.

[2] A. M. Rizwan, L. Y. C. Dennis, and C. Liu, "A review on the generation, determination and mitigation of Urban Heat Island," Journal of Environmental Sciences, vol. 20, no. 1, pp. 120 $128,2008$.

[3] M. Georgescu, P. E. Morefield, B. G. Bierwagen, and C. P. Weaver, "Urban adaptation can roll back warming of emerging megapolitan regions," Proceedings of the National Academy of Sciences of the United States of America, vol. 111, no. 8, pp. 29092914, 2014.

[4] S. Thorsson, F. Lindberg, I. Eliasson, and B. Holmer, "Different methods for estimating the mean radiant temperature in an outdoor urban setting," International Journal of Climatology, vol. 27, no. 14, pp. 1983-1993, 2007.

[5] N. Kántor and J. Unger, "Benefits and opportunities of adopting GIS in thermal comfort studies in resting places: an urban park as an example," Landscape and Urban Planning, vol. 98, no. 1, pp. 36-46, 2010.

[6] M. Köhler, "Green facades-a view back and some visions," Urban Ecosystems, vol. 11, no. 4, pp. 423-436, 2008.

[7] G. Pérez, L. Rincón, A. Vila, J. M. González, and L. F. Cabeza, "Green vertical systems for buildings as passive systems for energy savings," Applied Energy, vol. 88, no. 12, pp. 4854-4859, 2011.

[8] E. A. Eumorfopoulou and K. J. Kontoleon, "Experimental approach to the contribution of plant-covered walls to the thermal behaviour of building envelopes," Building and Environment, vol. 44, no. 5, pp. 1024-1038, 2009.

[9] R. M. Pulselli, F. M. Pulselli, U. Mazzali, F. Peron, and S. Bastianoni, "Emergy based evaluation of environmental performances of living wall and grass wall systems," Energy and Buildings, vol. 73, pp. 200-211, 2014.

[10] A. M. Hunter, N. S. G. Williams, J. P. Rayner, L. Aye, D. Hes, and S. J. Livesley, "Quantifying the thermal performance of green façades: a critical review," Ecological Engineering, vol. 63, pp. 102-113, 2014.

[11] R. Djedjig, E. Bozonnet, and R. Belarbi, "Experimental study of the urban microclimate mitigation potential of green roofs and green walls in street canyons," International Journal of LowCarbon Technologies, 2013.

[12] T. Koyama, M. Yoshinaga, H. Hayashi, K.-I. Maeda, and A. Yamauchi, "Identification of key plant traits contributing to the cooling effects of green façades using freestanding walls," Building and Environment, vol. 66, pp. 96-103, 2013. 
[13] R. W. F. Cameron, J. E. Taylor, and M. R. Emmett, "What's 'cool' in the world of green façades? How plant choice influences the cooling properties of green walls," Building and Environment, vol. 73, pp. 198-207, 2014.

[14] G. Gross, "Effects of different vegetation on temperature in an urban building environment. Micro-scale numerical experiments," Meteorologische Zeitschrift, vol. 21, no. 4, pp. 399-412, 2012.

[15] C. L. Tan, N. H. Wong, and S. K. Jusuf, "Effects of vertical greenery on mean radiant temperature in the tropical urban environment," Landscape and Urban Planning, vol. 127, pp. 5264, 2014.

[16] R. Berry, S. J. Livesley, and L. Aye, “Tree canopy shade impacts on solar irradiance received by building walls and their surface temperature," Building and Environment, vol. 69, pp. 91-100, 2013.

[17] Y.-C. Chen, T.-P. Lin, and A. Matzarakis, "Comparison of mean radiant temperature from field experiment and modelling: a case study in Freiburg, Germany," Theoretical and Applied Climatology, vol. 118, no. 3, pp. 535-551, 2014.

[18] S. Huttner, Further development and application of the $3 D$ microclimate simulation ENVI-met [Ph.D. thesis], Johannes Gutenberg-Universität Mainz, 2012.

[19] R.-L. Hwang, T.-P. Lin, and A. Matzarakis, "Seasonal effects of urban street shading on long-term outdoor thermal comfort," Building and Environment, vol. 46, no. 4, pp. 863-870, 2011.

[20] E. L. Krüger, F. O. Minella, and A. Matzarakis, "Comparison of different methods of estimating the mean radiant temperature in outdoor thermal comfort studies," International Journal of Biometeorology, vol. 58, no. 8, pp. 1727-1737, 2013.

[21] T.-P. Lin, A. Matzarakis, and R.-L. Hwang, "Shading effect on long-term outdoor thermal comfort," Building and Environment, vol. 45, no. 1, pp. 213-221, 2010.

[22] A. Matzarakis, F. Rutz, and H. Mayer, "Modelling radiation fluxes in simple and complex environments-application of the RayMan model," International Journal of Biometeorology, vol. 51, no. 4, pp. 323-334, 2007.

[23] A. Matzarakis, F. Rutz, and H. Mayer, "Modelling radiation fluxes in simple and complex environments: basics of the RayMan model," International Journal of Biometeorology, vol. 54, no. 2, pp. 131-139, 2010.

[24] F. Lindberg, B. Holmer, and S. Thorsson, "SOLWEIG 1.0modelling spatial variations of $3 \mathrm{D}$ radiant fluxes and mean radiant temperature in complex urban settings," International Journal of Biometeorology, vol. 52, no. 7, pp. 697-713, 2008.

[25] F. Lindberg and C. S. B. Grimmond, "The influence of vegetation and building morphology on shadow patterns and mean radiant temperatures in urban areas: model development and evaluation," Theoretical and Applied Climatology, vol. 105, no. 34, pp. 311-323, 2011.

[26] M. Srivanit and K. Hokao, "Evaluating the cooling effects of greening for improving the outdoor thermal environment at an institutional campus in the summer," Building and Environment, vol. 66, pp. 158-172, 2013.

[27] W. T. L. Chow and A. J. Brazel, "Assessing xeriscaping as a sustainable heat island mitigation approach for a desert city," Building and Environment, vol. 47, no. 1, pp. 170-181, 2012.

[28] W. T. L. Chow, R. L. Pope, C. A. Martin, and A. J. Brazel, "Observing and modeling the nocturnal park cool island of an arid city: horizontal and vertical impacts," Theoretical and Applied Climatology, vol. 103, no. 1-2, pp. 197-211, 2011.
[29] R. Emmanuel and H. J. S. Fernando, "Urban heat islands in humid and arid climates: role of urban form and thermal properties in Colombo, Sri Lanka and Phoenix, USA," Climate Research, vol. 34, no. 3, pp. 241-251, 2007.

[30] B. C. Hedquist and A. J. Brazel, "Seasonal variability of temperatures and outdoor human comfort in Phoenix, Arizona, U.S.A," Building and Environment, vol. 72, pp. 377-388, 2014.

[31] A. Middel, K. Häb, A. J. Brazel, C. A. Martin, and S. Guhathakurta, "Impact of urban form and design on midafternoon microclimate in Phoenix Local Climate Zones," Landscape and Urban Planning, vol. 122, pp. 16-28, 2014.

[32] N. Müller, W. Kuttler, and A.-B. Barlag, "Counteracting urban climate change: adaptation measures and their effect on thermal comfort," Theoretical and Applied Climatology, vol. 115, no. 1-2, pp. 243-257, 2014.

[33] E. Ng, L. Chen, Y. Wang, and C. Yuan, "A study on the cooling effects of greening in a high-density city: an experience from Hong Kong," Building and Environment, vol. 47, no. 1, pp. 256271, 2012.

[34] L. L. H. Peng and C. Y. Jim, "Green-roof effects on neighborhood microclimate and human thermal sensation," Energies, vol. 6, no. 2, pp. 598-618, 2013.

[35] C. Skelhorn, S. Lindley, and G. Levermore, "The impact of vegetation types on air and surface temperatures in a temperate city: a fine scale assessment in Manchester, UK," Landscape and Urban Planning, vol. 121, pp. 129-140, 2014.

[36] X. Yang, L. Zhao, M. Bruse, and Q. Meng, "Evaluation of a microclimate model for predicting the thermal behavior of different ground surfaces," Building and Environment, vol. 60, pp. 93-104, 2013.

[37] I. D. Stewart and T. R. Oke, "Local climate zones for urban temperature studies," Bulletin of the American Meteorological Society, vol. 93, no. 12, pp. 1879-1900, 2012.

[38] M. Bruse and H. Fleer, "Simulating surface-plant-air interactions inside urban environments with a three dimensional numerical model," Environmental Modelling and Software, vol. 13, no. 3-4, pp. 373-384, 1998.

[39] N. H. Wong, A. Y. Kwang Tan, Y. Chen et al., “Thermal evaluation of vertical greenery systems for building walls," Building and Environment, vol. 45, no. 3, pp. 663-672, 2010.

[40] M. Bruse, Die Auswirkungen kleinskaliger Umweltgestaltung auf das Mikroklima [Ph.D. thesis], Universität Bochum, 1999.

[41] C. J. Willmott, S. G. Ackleson, R. E. Davis et al., "Statistics for the evaluation and comparison of models," Journal of Geophysical Research, vol. 90, no. 5, pp. 8995-9005, 1985.

[42] K. H. Schlünzen and R. S. Sokhi, "Overview of tools and methods for meteorological and air pollution mesoscale model evaluation and user training," WMO Joint Report COST Action 728 GURME, 2008.

[43] F. Ali-Toudert, Dependence of outdoor thermal comfort on street design in hot and dry climate [Ph.D. thesis], Universität Freiburg, Freiburg im Breisgau, Germany, 2005.

[44] F. Yang, S. S. Y. Lau, and F. Qian, “Thermal comfort effects of urban design strategies in high-rise urban environments in a sub-tropical climate," Architectural Science Review, vol. 54, no. 4, pp. 285-304, 2011.

[45] S. Berkovic, A. Yezioro, and A. Bitan, "Study of thermal comfort in courtyards in a hot arid climate," Solar Energy, vol. 86, no. 5, pp. 1173-1186, 2012. 

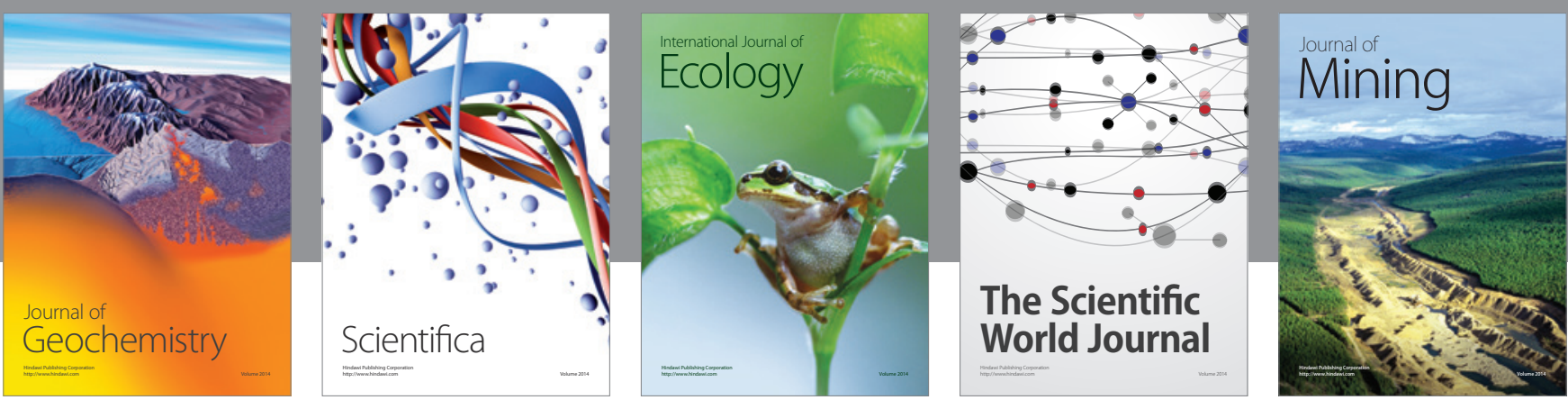

The Scientific World Journal
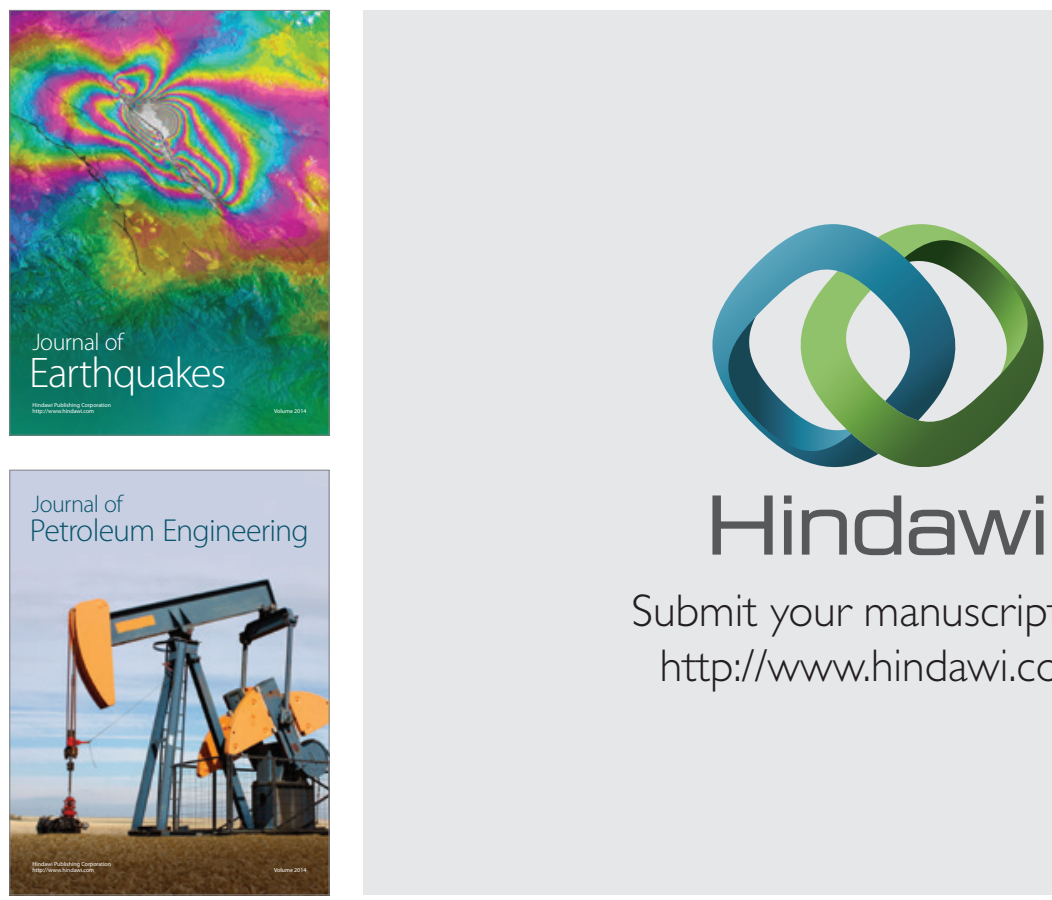

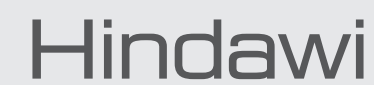

Submit your manuscripts at

http://www.hindawi.com
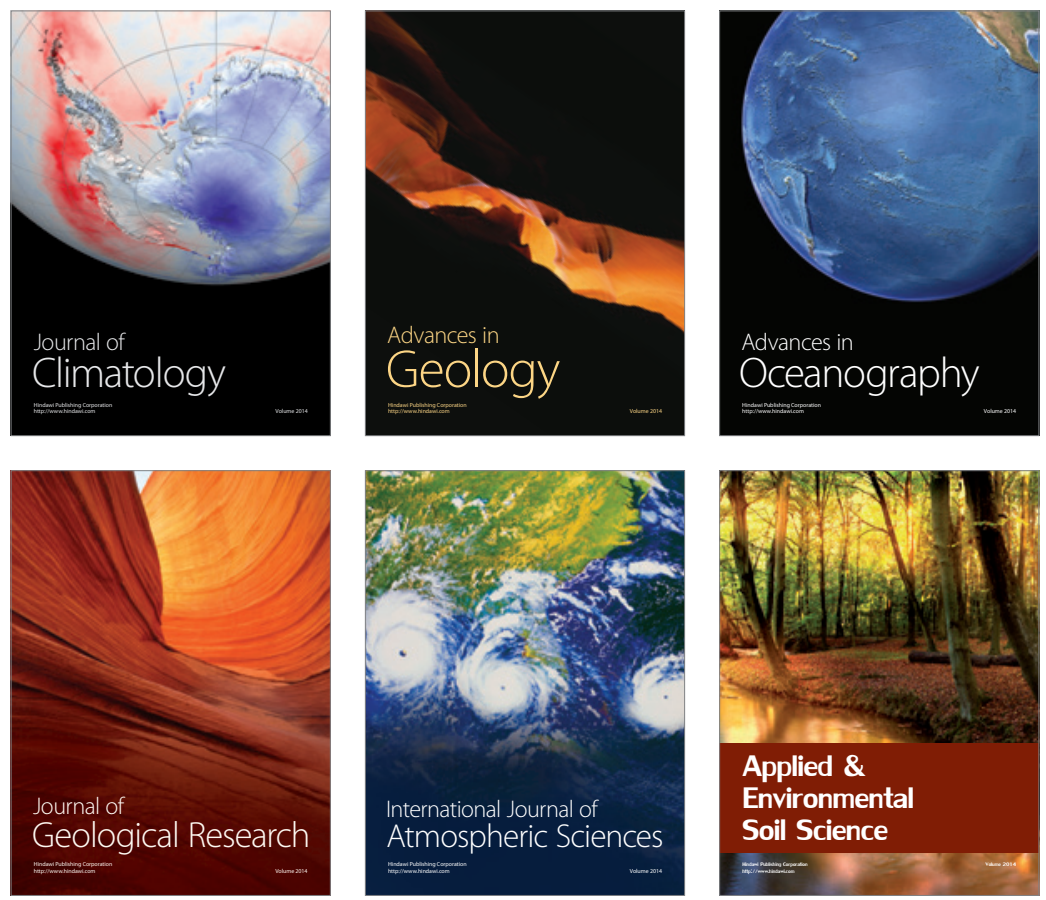
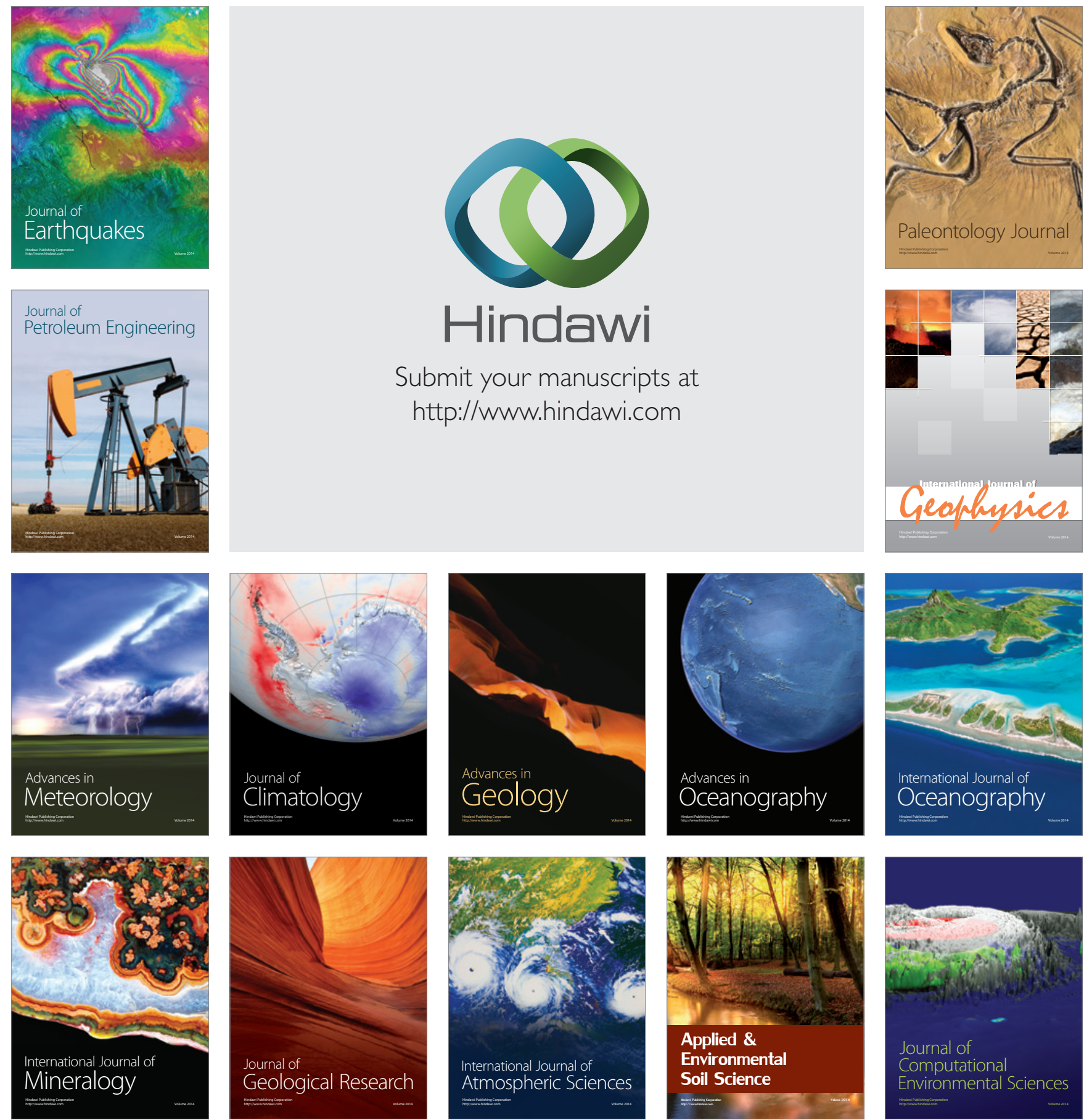